\title{
Demonstration of Aerosol Property Profiling by multi-wavelength Lidar under Varying Relative \\ Humidity Conditions
}

\author{
I. Veselovskii ${ }^{(1)}$, D.N. Whiteman ${ }^{(2)}$, A. Kolgotin ${ }^{(1)}$, E. Andrews ${ }^{(3)}$, M.Korenskii ${ }^{(1)}$ \\ ${ }^{(1)}$ Physics Instrumentation Center, Troitsk, Moscow Region, 142190, Russia. E-mai: \\ igorv@pic.troitsk.ru \\ ${ }^{(2)} N A S A$ GSFC, Greenbelt MD 20771, USA. E-mail: david.n.whiteman@nasa.gov \\ ${ }^{(3)}$ CIRES, University of Colorado, Boulder, CO 80305, USA. E-mai: Betsy.Andrews@noaa.gov
}

\begin{abstract}
The feasibility of using a multi-wavelength Mie-Raman lidar based on a tripled Nd:YAG laser for profiling aerosol physical parameters in the planetary boundary layer (PBL) under varying conditions of relative humidity $(\mathrm{RH})$ is studied. The lidar quantifies three aerosol backscattering and two extinction coefficients and from these optical data the particle parameters such as concentration, size and complex refractive index are retrieved through inversion with regularization. The columnintegrated, lidar-derived parameters are compared with results from the AERONET sun photometer. The lidar and sun photometer agree well in the characterization of the fine mode parameters, however the lidar shows less sensitivity to coarse mode. The lidar results reveal a strong dependence of particle properties on $\mathrm{RH}$. The height regions with enhanced $\mathrm{RH}$ are characterized by an increase of backscattering and extinction coefficient and a decrease in the Ångström exponent coinciding with an increase in the particle size. We present data selection techniques useful for selecting cases that can support the calculation of hygroscopic growth parameters using lidar. Hygroscopic growth factors calculated using these techniques agree with expectations despite the lack of co-located radiosonde data
\end{abstract}


Despite this limitation, the results demonstrate the potential of multi-wavelength Raman lidar technique for study of aerosol humidification process.

\section{INTRODUCTION}

The radiation balance of the Earth is strongly influenced by atmospheric aerosols of natural and anthropogenic origin (D’Almeida et al. 1991; Pilinis et al. 1995). For accurate modeling of corresponding radiative forcing knowledge of the vertical distribution of particle macro- and microphysical parameters is needed. During recent years ground-based and airborne lidars have become important tools for profiling tropospheric aerosols using either single or multiple wavelengths (Kovalev and Eichinger 2004). For quantitative studies of the optical properties of tropospheric aerosol, Raman lidars have proven to be most useful (Ansmann et al. 1992; Ferrare et al. 1998a,b; Ansmann et al. 2000; Turner et al. 2002). This lidar type measures elastically backscattered light simultaneously with Raman backscatter from molecules (nitrogen or oxygen), thus allowing independent calculation of particle backscattering and extinction coefficients without the need of critical assumptions about atmospheric parameters. Still, to invert the measured aerosol scattering coefficients to the particle microphysical parameters when only a single output wavelength is used, physical models with numerous a priori assumptions are generally needed.

On the other hand, the application of multi-wavelength (MW) Raman lidar can be used to quantify the main particle microphysical parameters with fewer a priori assumptions. Information on the particle extinction and backscatter coefficients at multiple wavelengths is produced by such lidars and, with this information, microphysical properties of aerosols can be retrieved through mathematical inversion (Müller et al. 1999; Veselovskii et al. 2002). Theoretical and experimental studies performed 
during the last decade have demonstrated that the MW lidar technique is able to provide comprehensive information about aerosol microphysical parameters (Muller et al. 2004, 2005; Veselovskii et al. 2004, 2005) although simulation studies have shown a decreasing sensitivity as particle size increases. These results demonstrate that the key to the successful retrieval of aerosol parameters is the joint use of aerosol backscattering and extinction coefficients, which can be accomplished through the use of Raman or high spectral resolution methods (Shipley et al. 1983; Liu 2002). Another important finding is that a simplified multi-wavelength Raman lidar based on a frequency-tripled Nd:YAG laser can be used to quantify the particle size distribution (PSD) and complex refractive index (Müller et al. 2001; Veselovskii et al. 2004, 2005).

To study this technique further the lidar-derived parameters should be compared with comparable results from other instruments. One of the recognized instruments for retrieval of columnintegrated aerosol properties is the robotic sun photometer (SP) that is used in the network called AERONET (Holben et al. 1998, Dubovik et al. 2002). The comparison of lidar and sun photometer data has been performed in previous publications (Muller et al. 2004) as a method to assess the performance of the multi-wavelength lidar technique. We also compare lidar-derived results with sun photometer, however we emphasize the height variation under different atmospheric conditions revealed by lidar versus the column-integrated quantities measured by the sun photometer.

One of the key factors influencing the scattering properties of aerosols is their hygroscopicity. As the relative humidity $(\mathrm{RH})$ rises, uptake of water vapor by hygroscopic aerosols increases the particle size, which generally leads to an increase in light-scattering (Hanel 1976). Numerous experimental studies of the relationship between aerosol scattering and relative humidity have been performed in the laboratory with aerosols of known chemical composition (Tang and Munkelwitz 
1993; Fuzzi et al. 2001; Kumar et al. 2003; Svenningsson et al. 2006; Kreidenweis et al. 2006). In-situ experiments in the natural environment have also been performed using nephelometers (Kotchenruther et al. 1998, 1999; Carrico 2003) and differential mobility analyzers (Gasparini et al. 2006a,b) in tandem with humidity control systems. Under the right conditions, a lidar may provide another tool for studying aerosol hygroscopicity. The advantage of using a lidar (as opposed to laboratory or most insitu studies) is that it can provide relatively continuous altitude-resolved measurements of aerosol properties without perturbing the aerosol or its surroundings. The obvious disadvantage is that, because the aerosol sampled by the lidar is not controlled in any way (e.g., source, state, etc), lidar studies of aerosol hygroscopicity need to be limited to occasions when the same aerosol type exists in at least a portion of a profile that is characterized by widely changing $\mathrm{RH}$ so that observed differences in aerosol properties can be attributed primarily to water uptake as RH increases.

The enhancement of lidar backscatter due to particle swelling was first considered by MacKinnon, 1969. Since then numerous studies have investigated the relationship between aerosol backscattering and relative humidity (Ferrare et al. 1998b; Pahlow et al. 2006; Wulfmeyer and Feingold 2000; Feingold and Morley 2003; Raut and Chazette 2007). The water vapor mixing ratio in these more recent studies was derived from either lidar measurements, Raman (Ferrare et al. 1998; Pahlow et al. 2006) and differential absorption (Wulfmeyer and Feingold 2000), or was calculated under a boundary layer cloud deck suggesting a well-mixed boundary layer (Feingold and Morley 2003). If the boundary layer is well mixed, then any change in backscatter in the vertical is considered to be due to uptake of water vapor by the particles. Assuming the atmosphere is saturated at cloud base and assuming that the potential temperature is constant with height, the relative humidity $(\mathrm{RH})$ profile can be calculated (Pahlow et al. 2006; Wulfmeyer and Feingold 2000; Feingold and Morley 2003). 
Using single-wavelength backscatter lidar data combined with thermodynamic assumptions of the mixing state of the atmosphere allows for the determination of the hygroscopic growth factor $f(\mathrm{RH})$ for relative humidities close to saturation. The growth factor is calculated in terms of backscattering at a given $\mathrm{RH}$, relative to some lower $\mathrm{RH}_{\text {ref. }}$ The application of the multi-wavelength Raman lidar technique has an advantage over single-wavelength measurements because it increases the amount of available information allowing derivation of the particle size distribution and other physical properties along with the water vapor mixing ratio.

The possibility of using the multi-wavelength lidar method for the study of cloud condensation nuclei was considered by Feingold and Grund in 1994, but experimental implementation of this method is more recent. The increase of particle size and extinction coefficient near the PBL top derived from multi-wavelength lidar measurements during the ACE 2 (Aerosol Characterization Experiment) field campaign has been reported (Müller et al. 2002; Ansmann et al. 2002). As inversion routines and retrievals improve and additional aerosol products become available (e.g., PSDs, refractive index), the use of multi-wavelength lidar to investigate aerosol hygroscopicity may provide new insights into the aerosol properties relevant for climate forcing in the atmosphere.

The goal of this paper is to derive vertical profiles of aerosol physical parameters in the PBL from multi-wavelength lidar measurements under varying relative humidity conditions and to compare the column-integrated aerosol parameters with results from the AERONET sun photometer. To demonstrate the potential of the multi-wavelength technique to study aerosol hygroscopic growth, data selection techniques are used to assess the mixing of aerosols in the PBL and hygroscopic growth factors are calculated for the best of these cases. 


\section{Lidar system description}

The experiments described here were performed with a multi-wavelength Mie-Raman lidar developed at NASA/GSFC. The lidar is based on a Continuum 9050 laser with a $50 \mathrm{~Hz}$ repetition rate. The output powers at $\lambda=355,532$ and $1064 \mathrm{~nm}$ were $17.5,7.5$ and $14 \mathrm{~W}$ respectively. The backscattered light was collected by a Meade LPX200 40-cm aperture Schmidt-Cassegrain telescope operated at 0.35 mrad field-of-view and inclined so that the elevation angle was 18 degrees. The offvertical measurements obtained through this approach improve the extraction of parameters in the PBL by decreasing the altitude to which the lidar overlap function influences the retrievals. The collected light passes through an optical fiber to a receiving module, which includes an off-axis parabolic mirror for collimation. The spectral components of the collimated optical signal are separated by dichroic beam splitters and interference filters. In the current configuration the system is capable of detecting three backscattered and two nitrogen Raman signals at $\lambda_{R}=387$ and $607 \mathrm{~nm}$. The receiving module also has the ability to measure the water vapor and liquid water. Raman signals at 407.5 and $402 \mathrm{~nm}$, respectively (Whiteman and Melfi 1999), although no liquid water data are analyzed here. The detection in the 355-532 nm range is performed with Hamamatsu R1924 PMTs; for the $607 \mathrm{~nm}$ channel a Hamamatsu H7422P-40 module is used; and backscatter at $1064 \mathrm{~nm}$ is measured with an IR enhanced Si APD (Licel APD-3.0) operating in analog mode. The outputs of the detectors are recorded at $7.5 \mathrm{~m}$ range resolution with a Licel data acquisition system that incorporates both analog and photon-counting electronics.

\section{Raman Lidar calculation techniques}


The combined use of Rayleigh-Mie and Raman backscatters allows independent calculation of the particle backscattering $\beta$ and extinction $\alpha$ coefficients at 355 and $532 \mathrm{~nm}$ (Ansmann et al. 1998). Computation of $\beta_{1064}$ is performed from the backscattered signal using the following form of the lidar equation:

$$
P_{\lambda}(z)=A_{\lambda} \frac{1}{z^{2}}\left[\beta_{\lambda}^{m}(z)+\beta_{\lambda}^{a}(z)\right] \exp \left[-2 \int_{0}^{z}\left(\alpha_{\lambda}^{m}(z)+\alpha_{\lambda}^{a}(z)\right) d z\right]
$$

with the boundary condition of $\beta_{\lambda}^{a}\left(z_{r e f}\right)=0$, where $\mathrm{P}_{\lambda}(\mathrm{z})$ is the backscattered power, $\mathrm{A}_{\lambda}$ is a range independent calibration parameter, $\beta_{\lambda}^{m}, \beta_{\lambda}^{a}, \alpha_{\lambda}^{m}, \alpha_{\lambda}^{a}$ are molecular (Raleigh) and aerosol backscattering and extinction coefficients at wavelength $\lambda$. The temperature dependence of Raman scattering has been neglected in these calculations due to the relatively mild change in atmospheric temperature over the altitude ranges involved (Whiteman 2003a, 2003b). The extinction profile at $1064 \mathrm{~nm}$ is derived by extrapolating Raman measurements at $532 \mathrm{~nm}$ through the relationship $\frac{\alpha_{\lambda_{1}}^{a}}{\alpha_{\lambda_{2}}^{a}}=\left(\frac{\lambda_{2}}{\lambda_{1}}\right)^{k}$, where the Ångström coefficient $k$ is calculated from the $\frac{\alpha_{355}}{\alpha_{532}}$ ratio obtained from the lidar data and assumed constant over the wavelength range. The reference distance $z_{\text {ref }}$ is chosen above the PBL top where aerosol contribution to backscatter is negligible. A typical lidar signal at $1064 \mathrm{~nm}$ is presented in Fig.1. It shows that for distance $\mathrm{z}_{\mathrm{ref}}>14 \mathrm{~km}$ (for height above $4.2 \mathrm{~km}$ ) the lidar signal is mainly due to molecular scattering.

The sensitivity of the calculated backscatter and extinction coefficients to the Ångström coefficient, $k$, is generally mild (Whiteman 2003a) when using the standard Raman lidar technique (Whiteman et al. 1992). However, these previous results refer to soundings acquired vertically. For 
small sounding angles with respect to the horizon, the optical depth of the sounding path is increased significantly and so is the sensitivity to $k$ and its range dependence $k(z)$. It should be mentioned that the Ångström coefficient affects extinction and backscattering in different ways. The uncertainty in the extinction $\alpha_{\lambda}(z) \square\left(1+\left(\frac{\lambda}{\lambda_{R}}\right)^{k(z)}\right)^{-1}$, where $\lambda_{\mathrm{R}}$ - the wavelength of the Raman scattered signal, is determined by the fully propagated uncertainties in $k(z)$. The backscattering coefficient $\beta(z) \square \int_{z_{\text {ref }}}^{z} \alpha_{\lambda}(\xi)\left(1-\left(\frac{\lambda}{\lambda_{R}}\right)^{k(\xi)}\right) d \xi$, and the uncertainties are integrated when moving away from the reference point. In our computations we use range dependent Ångström coefficient $k(z)$ derived from the extinction ratio $\frac{\alpha_{355}}{\alpha_{532}}$ and neglect the spectral variation of $k$. From the computations performed for different $k$ we conclude that the extinction is not very sensitive to variations in $k$, with corresponding uncertainties generally being less than $4 \%$. However, for backscattering the use of a range-dependent $k$ is essential. For some cases studied here, the uncertainty in the retrieval of $\beta_{355}$ at a height h=500 m can increase by as much as $10 \%$ if the range variation in $k$ is not considered. When calculating $\beta_{1064}$, the approximation that $k$ is spectrally independent in the $532-1064 \mathrm{~nm}$ range may appear too coarse. However, the aerosol extinction at $1064 \mathrm{~nm}$ is much lower than at $532 \mathrm{~nm}$, so the backscattering at $1064 \mathrm{~nm}$ is not very sensitive to spectral or range variations of the Ångström coefficient. Based on these considerations, we estimate the uncertainty of both the backscattering and extinction calculation inside PBL to be less than $10 \%$. Typical vertical profiles of backscattering and extinction coefficients at different wavelengths measured on August 22 are shown in Fig.2. 


\section{Retrieval of particle microphysical parameters}

The lidar- derived backscattering and extinction coefficients are then used to calculate aerosol microphysical properties through inversion. The main features of our retrieval algorithm, which is based on inversion with regularization (Twomey 1977; Tikhonov and V.Y.Arsenin 1977), are presented elsewhere (Veselovskii et al. 2002; 2004). The algorithm makes no assumption about optical data input errors. The only constraints on the permitted refractive index and particle size distribution are that the refractive index is considered to be wavelength independent and that the concentration of the particles with radii below some $r_{\min }$ and above some $r_{\max }$ is zero, where the values of these radii are found in the process of inversion. Furthermore, in the retrieval we don't consider particles outside the radii interval $0.05 \mu \mathrm{m}-10 \mu \mathrm{m}$, i.e. these are the limiting values of $r_{\min }$ and $r_{\max }$.

The algorithm was initially designed for retrievals at a single height layer, but in data analysis usually the whole vertical profile of particle parameters is desired. In principle, the profile can be obtained from the retrievals at every layer, though such procedure is time consuming and does not take into consideration the likely interdependence of aerosol properties between two closely spaced layers. In the new version of the algorithm we have introduced modifications to overcome these limitations.

At any height layer the measured optical data $g_{i}$ (backscattering or extinction) are related to the size distribution $f(r)$ through the Fredholm integral equation:

$$
\int_{r_{\min }}^{r_{\max }} K_{i}(m, \lambda, r) f(r) d r=g_{i} \quad i=1, . ., \mathrm{L}
$$

where $K_{i}(m, r, \lambda)$ are the kernel functions for refractive index $m$ and wavelength $\lambda$ calculated with Mie theory. Particle size distribution is approximated by the superposition of base functions $B_{j}(r)$ as: 
$f(r)=\sum_{j=1}^{q} c_{j}(z) B_{j}(r)$,

where $c_{j}(z)$ are the weight coefficients. The base functions have a triangular shape on a logarithmicequidistant grid across the chosen radius interval $\left[\mathrm{r}_{\min }, \mathrm{r}_{\max }\right]$ in which the inversion is performed.

The integral equation (2) transforms to a linear one as follows:

$g_{i}=\sum_{j=1}^{q} A_{i j} c_{j}$.

where the elements of weight matrix $\mathrm{A}_{\mathrm{ij}}$ are calculated as:

$$
A_{i j}=\int_{r_{\min }}^{r_{\max }} K_{i}(m, \lambda, r) B_{j}(r) d r .
$$

At any of $l$ height layers the expression (4) can be written in matrix-vector form as:

$$
\mathbf{A}^{l} \mathbf{c}^{l}=\mathbf{g}^{l} \quad l=1, \ldots, \mathrm{N}_{\mathrm{L}}
$$

or it can be expressed in more general form for the whole height range:

$$
\mathbf{A C}=\mathbf{G}
$$

In the new version of algorithm the equation (7) is solved for all layers simultaneously by means of inversion with regularization:

$$
\mathbf{C}=\left(\mathbf{A}^{T} \mathbf{A}+\gamma \mathbf{H}\right)^{-1} \mathbf{A}^{T} \mathbf{G}
$$

where $\gamma$ is the regularization parameter. Matrices $\mathbf{A}, \mathbf{H}$ and vectors $\mathbf{C}, \mathbf{G}$ have the following structure (Kolgotin and Muller 2008): 



$$
\left.\mathbf{G}=\left(\left[\mathbf{g}^{(1)}\right]_{L \times 1}:\left[\mathbf{g}^{(2)}\right]_{L \times 1}: \ldots: \mathbf{g}^{\left(N_{L}\right)}\right]_{L \times 1}\right)_{N_{L} L \times 1}^{\mathrm{T}}
$$

As shown in our previous publications (Veselovskii et al. 2002, 2004), the averaging of solutions in the vicinity of the minimum of discrepancy helps to stabilize the inversion. In the previous version of the algorithm the choice of the averaging interval was made for each layer separately. In the new version used here, all layers are processed simultaneously. The procedure includes the following steps:

- $\quad$ For every $k$-th solution the discrepancy $\rho_{k}$ is calculated (Veselovskii et al. 2002, 2004). At each height layer the solutions are ordered in accordance with their discrepancy $\rho_{k}$, from small discrepancy to largest discrepancy.

- At every height layer we calculate the discrepacy $\widetilde{\rho}^{(l)}\left(n_{k}\right)$ for the first $n_{k}$ averaged solutions.

- The total discrepancy for the whole height profile is then calculated as $\tilde{\rho}^{\mathrm{tot}}\left(n_{k}\right) \approx \frac{1}{\mathrm{~N}_{\mathrm{L}}} \sum_{l=1}^{\mathrm{N}_{\mathrm{L}}} \tilde{\rho}^{(l)}\left(n_{k}\right)$ 
To estimate the number of solutions to be averaged it is convenient to consider the dependence of $\widetilde{\rho}^{\text {tot }}$ on the individual $\rho_{k}$, i.e. $\tilde{\rho}^{\text {tot }}\left(\rho_{k}\right)$. Thus at every layer we sum the solutions with discrepancy smaller than $\rho_{k}$. The analysis of the function $\widetilde{\rho}^{\text {tot }}\left(\rho_{k}\right)$ permits the determination of the optimal solution set for

all layers simultaneously where in general the optimum $\rho_{k}$ yields a stable $\tilde{\rho}^{\text {tot }}\left(\rho_{k}\right)$ such that the increase of $\rho_{k}$ does not lead to a significant change in the derived microphysical parameters.

The typical uncertainties of the retrievals studied here were estimated from modeling and from the scatter of the individual solutions to be $20 \%$ for volume density and effective radius, $25 \%$ for mean radius and $40 \%$ for number density. These uncertainty values are applied as typical throughout all cases and will be represented by the error bars on the solutions.

\section{Site and Measurement Characteristics}

The measurements analyzed here were performed during August and September 2006 at NASA/GSFC $(38.99 \mathrm{~N},-76.84 \mathrm{~W})$. This season in the vicinity of Washington DC is frequently characterized by hazy, high humidity conditions and thus provides an excellent opportunity for the study of aerosol growth due to humidification. Such conditions are also advantageous for the comparison of lidar with sun photometer, because the majority of aerosols are concentrated inside the planetary boundary layer (PBL) thus implying that particles are reasonably spherical and that the fine mode dominates the PSD (Dubovik et al. 2002).

For studying particle variation within the PBL it is desirable to perform the measurements starting from low altitudes. Therefore, as mentioned before, the lidar system was operated at an angle of 18 degrees with respect to the horizontal so as to minimize the vertically-resolved height to which the measurements were influenced by the lidar overlap function. Using this approach, backscattering 
and extinction coefficients could be calculated starting from an altitude as low as $0.5 \mathrm{~km}$ above ground level. Measurements were performed during the nighttime, between 9-10 pm local time (01:00-02:00 UT), which was approximately 2 hours later than the last sun photometer measurement and approximately 1 hour past twilight.

Particle behavior as a function of $\mathrm{RH}$ is dependent upon composition and may range from hydrophobic to strongly hygroscopic with monotonic (smoothly varying) or deliquescent (step change) growth. Ambient aerosols typically found in the NASA/GSFC area consist mainly of sulfate material (Dubovik et al. 2002; Chen et al. 2002) and therefore significant growth of the particles can be expected for RH $>\sim 80 \%$. Laboratory studies of sulfate-containing particles (Tang 1996) and field studies in the vicinity of NASA/GSFC bear this out (Kotchenruther et al. 1999; Fitzgerald et al. 1982). The value of $f(\mathrm{RH})$ (defined as the ratio of total scattering at $\mathrm{RH}=85 \%$ and $40 \%$, respectively) for typical east coast regional haze aerosol has been found to be approximately 2.0 (Kotchenruther et al. 1999; Fitzgerald et al. 1982). Increases in aerosol size over the same humidity range are on the order of 1.3 (Fitzgerald et al. 1982).

Profiles of atmospheric density, temperature and relative humidity (RH) were obtained from radiosonde measurements acquired at Dulles Airport, which is located approximately $50 \mathrm{~km}$ west of the lidar site. The radiosonde water vapor mixing ratio was calculated from these data using the Wexler formulation for saturation vapor pressure over a liquid surface (Wexler 1976). The radiosondes were launched at $00 \mathrm{UT}$, which was approximately 1-2 hours prior to the time of the lidar measurements. The radiosonde-derived water vapor mixing ratio data were used for the absolute calibration of the lidar water vapor mixing ratio measurements, which were calculated using the traditional Raman lidar technique (Whiteman et al. 1992). The relative humidity used in the analysis of 
hygroscopic growth was calculated using the temperature data from the radiosonde and water vapor mixing ratio derived from the lidar measurements.

\section{Data selection techniques and day-by-day examples}

Multi-wavelength lidar retrievals of aerosol properties are considered here on three days with differing relative humidity conditions: one day with low RH (August 16, 2006) and two days with high RH (August 27 and September 12, 2006), and consider, for these latter two cases, the possibility that the measurements reveal growth of a fixed aerosol mixture due to the hygroscopic uptake of water. A necessary condition for studying hygroscopic growth in the atmosphere using lidar is that the same aerosol mixture exists at all altitudes being studied. This is achieved when the atmosphere is wellmixed through convection or if similar aerosols are transported to the measurement site. With similar aerosols being present throughout a profile, any changes in particle size due to changes in RH can be attributed to water uptake or release by the aerosols and hygroscopic growth curves can potentially be calculated.

We used a variety of tools to determine whether well-mixed conditions of aerosols were expected to exist within the lidar profile. Back trajectory analysis was used to determine the source region of the aerosols as a function of altitude. If the source region for the aerosols was independent of altitude for a given case, we took this to be evidence of similar aerosol type existing in the lidar profiles. We also took the presence of an altitude-independent lidar-derived water vapor mixing ratio to be an indication of well-mixed conditions. Finally, we investigated the derived number density from the lidar itself. If this did not vary beyond the uncertainty bars of the retrieval, we also took this to be an indication of well-mixed conditions. We considered all three of these tests for the cases to be presented in the next section. As we will show, two of the three datasets, those of August 27 and 
September 12, 2006, were found to present a fixed aerosol mixture in a region of the profile. However only the latter case also provided the range of RHs needed to study hygroscopic growth. The weakness of the analysis presented here is that the temperature data used to convert the lidar mixing ratio into RH was provided by a radiosonde launched approximately $50 \mathrm{~km}$ from the lidar site. This introduces sufficient uncertainty in the temperature profile at the lidar site that the hygroscopic growth curves calculated here can only be taken as indicative of potential of the multi-wavelength technique.

\subsection{Measurements From August 16, 2006}

This day was characterized by low humidity and the absence of clouds. Fig.3a shows the vertical profiles of water vapor mixing ratio obtained from the lidar and radiosonde measurements. The shapes of the profiles are similar, supporting the use of the sonde data for calibration of the lidar water vapor mixing ratio. It also suggests that the meteorological conditions were similar between the location of the sonde launch and the lidar site. From this point forward in the manuscript, profiles will be shown with respect to the vertically resolved altitude $h$.

The lidar-derived RH profile agrees quite well with the sonde data, as is shown on Figure 3a. The RH on 16 August was below 65\% in the height interval of 1.0-1.8 km, so enhancement of the lidar backscatter due to particle hygroscopicity is expected to be small. The altitude dependence of aerosol properties measured and derived from the lidar on 16 August 2006 is shown in Fig.3b-e. The top of the boundary layer is at $\sim 1.9 \mathrm{~km}$ and it coincides with the drop of water vapor content. Both extinction and backscattering have a secondary maximum near the PBL top likely due to accumulation of aerosols. The Ångström exponent is found to rise with height in the PBL, which suggests that higher altitudes are dominated by smaller particles. This is confirmed by Fig.3c, showing the vertical profiles of mean and effective radius derived from the lidar data. In the interval between 1.0 and $1.8 \mathrm{~km}$, the retrieved 
mean radius indicates a decrease in particle size. The lack of particle size increase with height is consistent with RH conditions below the threshold for hygroscopic growth. Fig.3d shows the retrieved number and volume densities on August 16. From Fig.3d we conclude that the previously mentioned maximum in particle extinction at $\sim 1.8 \mathrm{~km}$ appears to be more likely due to an increase in particle number density than in particle size.

Because August 16 was cloudless it provided a good opportunity to compare the lidar and sun photometer retrievals. The column-integrated particle parameters derived from AERONET and lidar measurements are summarized in Table 1. To derive column-integrated particle parameters from lidar data, we summed the PSDs at each height layer assuming that the PSD was constant below the lowest lidar retrieval. From this column-integrated PSD mean, the effective radius and volume density were calculated. To get column-averaged refractive indices, the values of $m_{R}$ and $m_{I}$ in each layer were weighted by the volume density of the layer (weighting by extinction yielded similar results): $\bar{m}=\frac{\int_{0}^{h_{\max }} V(h) m(h) d h}{\int_{0}^{h_{\max }} V(h) d h}$.

Aerosol optical thicknesses provided by AERONET at 355 and $532 \mathrm{~nm}$ are $0.32 \pm 0.015$ and $0.18 \pm 0.009$. The corresponding values from lidar are $0.3 \pm 0.03$ and $0.18 \pm 0.018$. The agreement is good keeping in mind that we extrapolated the extinction by assuming that the lowest retrieved lidar extinction value at 500m was constant down to the surface. The effective radius $\mathrm{r}_{\text {eff }}$ obtained from inversion of sun photometer measurements was $r_{\text {eff }}^{\text {tot }}=0.22 \pm 0.02 \mu \mathrm{m}$ for the total particle size distribution (PSD) and $r_{\text {eff }}^{\text {fine }}=0.12 \pm 0.01 \mu \mathrm{m}$ for the fine mode, while the lidar retrievals for the total 
PSD show effective radius decreasing with height from $0.28 \mu \mathrm{m}$ to $0.12 \mu \mathrm{m}$ with an uncertainty of 0.04 $-0.06 \mu \mathrm{m}$. The effective radius derived from the height integrated PSD is $0.21 \pm 0.04 \mu \mathrm{m}$ for the total PSD and $0.15 \pm 0.03 \mu \mathrm{m}$ when only fine mode is considered. The height profiles of real $\mathrm{m}_{\mathrm{R}}$ and imaginary $m_{I}$ parts of refractive index are shown in Fig.3e. The uncertainty of the refractive index retrieval is estimated to be \pm 0.05 for the real part and $50 \%$ for the imaginary part. On 16 August $m_{R}$ rises with altitude from 1.4 to 1.5 , while $\mathrm{m}_{\mathrm{I}}$ stays constant at $\sim 0.01$ (within the retrieval uncertainty). The same figure shows $m_{R}$ and $m_{I}$ obtained from the sun photometer. The spectral variation of the indices is small according to the sun photometer retrievals: $\mathrm{m}_{\mathrm{R}}$ changes from 1.44 to 1.43 and $\mathrm{m}_{\mathrm{I}}$ from 0.0087 to 0.0094 in the $440-1020 \mathrm{~nm}$ spectral range supporting the use in this case of a spectrally invariant index of refraction in the lidar retrievals. Height averaged values of refractive index are $\bar{m}_{R}=1.45$ and $\bar{m}_{I}=0.01$, which are close to the results from AERONET. From this comparison we can conclude that the height-averaged values for both effective radius and refractive index derived from the lidar are in reasonable agreement with the results of sun photometer measurements.

Fig.4 shows the column-integrated PSD provided by the sun photometer. The distribution is bimodal with maximum at $0.11 \mu \mathrm{m}$ for fine and at $5 \mu \mathrm{m}$ for coarse mode. The same figure shows the lidar derived PSDs at the altitudes of 1.1 and $1.7 \mathrm{~km}$. The fine modes retrieved by the two instruments are in reasonable agreement, but the lidar-derived PSD begins to decrease for particles slightly larger than 1 um while the sun photometer PSD does not peak until 5 um. This result could be influenced by the fact that the size retrievals shown in fig $4 \mathrm{c}$ are increasing as height decreases, implying that larger particles may exist below the $0.5 \mathrm{~km}$ lower limit of the lidar retrievals. Another influence is the fact that the lidar retrievals, which use a maximum wavelength of $1064 \mathrm{~nm}$ ( 1 um), have decreasing sensitivity to particles with sizes greater than $\sim 2$ um. Simulations (Veselovskii et al. 2004) have shown, 
however, that the estimation of coarse mode parameters is possible although additional information such as would be provided through the use of longer wavelengths would be beneficial to the retrieval.

The columnar volume density from sun photometer was $0.056 \pm 0.005 \mu \mathrm{m}^{3} / \mu \mathrm{m}^{2}$ for total PSD and $0.029 \pm 0.004 \mu \mathrm{m}^{3} / \mu \mathrm{m}^{2}$ for the fine mode. The corresponding lidar-derived values are $0.035 \pm 0.007$ $\mu \mathrm{m}^{3} / \mu \mathrm{m}^{2}$ and $0.025 \pm 0.005 \mu \mathrm{m}^{3} / \mu \mathrm{m}^{2}$. In accordance with Fig.4 the main part of the lidar-derived density was contained in the fine mode and the corresponding value agrees well with the sun photometer measurements.

\subsection{Measurements from 27 August 2006}

The measurements on August 27, 2006 were performed under RH conditions sufficiently high to potentially support hygroscopic particle growth studies. At the time of the measurements, however, the back trajectories suggest that three separate air masses were influencing the vertical profile of aerosols present at the lidar site: 1) for the height region of $800-2000 \mathrm{~m}$, the origin of the air was generally southerly, 2) for the height region of $2350-2800 \mathrm{~m}$, the origin was generally south-westerly from the Virgina-Kentucky region and 3) for the height region of 2950-3400 m, the origin is also to the southwest but from the Alabama-Georgia region. Therefore, without sufficient mixing we would not expect to find the same type of aerosols at all altitudes thus preventing a clean determination of hygroscopic growth characteristics even if co-located radiosonde temperature data had been available. It should be noted that clouds were present on this day, which prevented any sun photometer retrievals from occurring so no comparisons with lidar were possible.

Fig.5 shows the retrievals for August 27. The top of the boundary layer is at $\sim 3.5 \mathrm{~km}$, the radiosonde and lidar measured $\mathrm{RH}$ profiles are quite similar and show relative humidity increasing with 
altitude from values below $50 \%$ at the bottom of the lidar retrieval around $500 \mathrm{~m}$ to above $90 \%$ for altitudes between 2.5 - $3.5 \mathrm{~km}$. The water vapor mixing ratio profile shows a slight decrease with altitude suggesting that the boundary layer may have been well-mixed during the daytime but that, at the times and locations of both the sonde launch and the lidar measurements, mixing was not complete in the boundary layer. The incomplete mixing present this day does not make this a good case for the study of hygroscopic growth. Nonetheless, the retrievals reveal a strong correlation between particle properties and RH. Inside the altitude range $0.5-1.8 \mathrm{~km}$ the particle size decreased slightly with height (Fig 5c). At an altitude of $1.8 \mathrm{~km}$, RH exceeded 80\% and the Ångström exponent at this height starts to decrease from 1.5 to 0, which indicates an increase in particle size as shown in Fig.5c. A decrease in the Ångström exponent is accompanied by an increase in the particle extinction and backscattering coefficients. The mean and effective radii grow rapidly above $2.0 \mathrm{~km}$ reaching $0.30 \mu \mathrm{m}$ and $0.6 \mu \mathrm{m}$ correspondingly. The fast growth of effective radius and volume density in the altitude interval 2.0 $3.3 \mathrm{~km}$ indicates the appearance of big particles resulting in an increase of extinction. The retrieved $\mathrm{m}_{\mathrm{R}}$ on August 27 was very close to that of pure water and varied from 1.32 to 1.36 in the height range considered. This variation in $\mathrm{m}_{\mathrm{R}}$ can be considered to be within retrieval uncertainty. The imaginary part decreases above $2.0 \mathrm{~km}$ as shown in Fig.5e. This could be attributable to water uptake in the regions of the aerosol population characterized by higher RH.

\subsection{Measurement from 12 September 2006}

In our measurement sessions, high humidity was usually observed during cloudy periods (e.g., August 27 (described above), so there were few opportunities to make a comparison between the lidar retrievals and those of sun photometer. One case where this was possible, however, occurred on 
September 12, 2006. The profiles of lidar-derived particle parameters for this case are shown in Fig.6 and the comparison of lidar and AERONET derived particles parameters is summarized in Table 2.

The back trajectory analysis for September 12 suggests that for the altitude regions of 1150 $2500 \mathrm{~m}$ at the lidar site, the origin of the aerosols was from a common region to the NW of the lidar site. We take this to imply that the aerosol mixture between these two altitudes is likely to be the same at the lidar site. This coupled with the wide range of RH present makes this case, of the three presented here, the one most likely to show hygroscopic growth behavior similar to more controlled in-situ studies and thus permit hygroscopic growth parameters to be calculated.

The RH shown in Fig 6 on September 12 exhibited an increase with altitude reaching a maximum at $1.5 \mathrm{~km}$ and then decreasing beyond $1.8 \mathrm{~km}$. The radiosonde data indicate saturated conditions between the altitudes of 1.2 and $2.0 \mathrm{~km}$ revealing the likely presence of a cloud. The lidar data, however, did not indicate the presence of a cloud illustrating again the desire to have co-located radiosonde data for studies such as these.

The altitude interval between 1.2 and $2.0 \mathrm{~km}$ is characterized by an increase in particle extinction from 0.05 to $0.4 \mathrm{~km}^{-1}$ at $355 \mathrm{~nm}$ and by a decrease in the Ångström exponent from 1.2 to 0.5 (Fig.6b). The Ångström exponent derived from the sun photometer at $340 \mathrm{~nm}$ and $500 \mathrm{~nm}$ wavelengths is approximately 0.9 , while lidar derived value varies from 0.4 to 1.8 . This is another example illustrating that significant changes in particle parameters can occur as a function of altitude that are masked by a column-integrated retrieval from the sun photometer.

The effective radius varies from 0.13 to $0.5 \mu \mathrm{m}$ while the column-integrated value from the sun photometer is $0.3 \pm 0.02 \mu \mathrm{m}$. The columnar volume concentrations from the sun photometer when the total PSD and only fine mode is considered are $0.073 \pm 0.007 \mu \mathrm{m}^{3} / \mu \mathrm{m}^{2}$ and $0.05 \pm 0.0075 \mu \mathrm{m}^{3} / \mu \mathrm{m}^{2}$ 
respectively. The corresponding lidar-derived values are of $0.076 \pm 0.015 \mu \mathrm{m}^{3} / \mu \mathrm{m}^{2}$ and $0.057 \pm 0.012$ $\mu \mathrm{m}^{3} / \mu \mathrm{m}^{2}$. Thus the results from both instruments are in reasonable agreement.

The real part of lidar-derived refractive index does not change much with altitude and the altitude-averaged value $\bar{m}_{R}=1.34 \pm 0.05$ agrees well with the sun photometer result $1.34 \pm 0.04$. The imaginary part $\mathrm{m}_{\mathrm{I}}$ derived from lidar varies with height between $0.015 \pm 0.0075$ and $0.007 \pm 0.0035$. The height averaged value of imaginary part derived from lidar is $\bar{m}_{I}=0.009 \pm 0.0045$, while for the sun photometer $\mathrm{m}_{\mathrm{I}}=0.05 \pm 0.0075$, thus these values are in agreement.

We also studied the correlation between the particle size and the Ångström exponent. Fig. 7 shows the dependence of effective radius on Ångström exponent for the ensemble of data. There is an inverse dependence of $k$ on $\mathrm{r}_{\text {eff }}$ that is nearly linear, implying that the lidar-derived $k$ can be used for a preliminary estimation of particle size. The same figure shows the results for AERONET measurements on 16 August and 12 September. These results are in good agreement with lidar measurements.

\section{Potential of multi-wavelength lidar for aerosol hygroscopic growth studies.}

As discussed in the earlier sections, the lidar measurements on September 12 were acquired under conditions considered to be supportive of hygroscopic growth (range of RH and similar aerosol type in the profile) while the data from August 27 were not. We will now consider the impact of RH on the particle parameters for these two cases taking the radiosonde temperature data to represent the temperature structure at the lidar site. The uncertainty in this assumption, due to the separation of the 
lidar and radiosonde sites, implies that the hygroscopic growth curves calculated from the lidar data should be taken as illustrating the potential of the technique and not as absolute quantifications.

The change of aerosol scattering properties as a function of RH is usually described by the humidification factor (or hygroscopic growth factor) $f(\mathrm{RH})$ used to characterize the response of a homogeneous mixture of aerosols that is subjected to changing values of RH. It is defined as the ratio between wet and dry scattering cross sections as follows:

$f(R H)=\frac{\alpha(R H)}{\alpha\left(R H_{r e f}\right)}$, where $\alpha\left(\mathrm{RH}_{\mathrm{ref}}\right)$ corresponds to the extinction coefficient at a low, reference $\mathrm{RH}$ value, which is obtained at some altitude level. The humidification factor $f(\mathrm{RH})$ can be parameterized using the Hänel model (Hänel 1976), as it was done by many investigators (Kotchenruther et al. 1998, 1999; Raut and Chazette 2007; Randriamiarisoa et al. 2006).

$\alpha=\alpha_{d r y}(1-R H)^{-g}$

where $\alpha_{\text {dry }}$ is the extinction of dry particles. For the reference value of RH this relationship can be rewritten as:

$\frac{\alpha}{\alpha_{r e f}}=\left(\frac{1-R H}{1-R H_{r e f}}\right)^{-g}$

We now calculate $\mathrm{f}(\mathrm{RH})$ from the data of August 27, when different source regions were identified in the data and mixing was incomplete, and September 12 where the measurement conditions are considered supportive of hygroscopic growth studies. The results for August 27 are shown in Fig 8 where a reference RH value of $60 \%$ was used. A general increase in $f$ is observed with increasing $\mathrm{RH}$, however the curve shows a great deal of scatter and differs significantly from the Hänel model results for $\mathrm{g}=0.9$, which is the best fit for 12 September results. We take the strong departure of the 
experimental curve from the simulated curve shown in fig 8 to reflect the fact that the conditions present on August 27 were not supportive of hygroscopic growth studies: different source regions of the aerosols were identified along with incomplete mixing indicating the likely presence of different aerosol types as a function of altitude in the profile. However, the general trend of increasing extinction as $\mathrm{RH}$ increases is consistent with the retrievals shown in figures 5 indicating that changing $\mathrm{RH}$ strongly influenced the profile of retrieved parameters.

Considering now data from September 12, when conditions were more suitable for hygroscopic growth studies, Fig. 9 shows the dependence of extinction coefficient at $532 \mathrm{~nm}$ on RH for three altitude ranges. The humidification factor $f(\mathrm{RH})$ is also shown in figure 9. Again, the reference value $\mathrm{RH}_{\text {ref }}$ was chosen to be $60 \%$, because lower values of $\mathrm{RH}$ were not accessible in these measurements. The value of $f(\mathrm{RH})$ at $\mathrm{RH}=80 \%$ in our measurements is 1.78 at $532 \mathrm{~nm}$. Using Figure 13 in Fitzgerald et al. 1982, an $f(\mathrm{RH})$ at $\lambda \sim 550 \mathrm{~nm}$ for the same humidity range is $\sim 1.45$. Using Figure 5 in Kotchenruther et al. 1999, $f(\mathrm{RH})$ values of $\sim 1.5$ and $\sim 1.7$ are obtained for clean and anthropogenicinfluenced air respectively over the same RH range. Thus the obtained values from the lidar are reasonably close to previous results for typical regional haze aerosol on the US East coast.

The best fit to experimental data at $532 \mathrm{~nm}$ for $\mathrm{RH}<85 \%$ is achieved at $g=0.9$, the corresponding curve for which is shown in Fig.9. The derived value of $g$ is in reasonable agreement with earlier studies (Randriamiarisoa et al. 2006) showing variation of this parameter between 0.27 and 1.35, so the derived value of $g$ looks reasonable. For $\mathrm{RH}$ exceeding $85 \%$ the lidar-derived humidification factor rises faster than the model prediction. This may be due to deliquescent growth implying that the simplified parameterization used in expression (14) is insufficient to describe the physics involved and that more complicated models may be needed (Kotchenruther et al. 1999). The 
hysteresis behavior displayed in Fig 9 may also indicate the presence of deliquescent compounds in the aerosols (Randriamiarisoa et al. 2006).

The multi-wavelength lidar technique also allows estimation of aerosol size growth factor $f_{r}(R H)=\frac{r(R H)}{r\left(R H_{r e f}\right)}$, which is the ratio between the wet and the quasi-dry particle radius. The dependence of the aerosol mean radius on RH together with size growth factor is shown in Fig.10. For comparison the same picture shows the hygroscopic growth of ammonium sulfate $\left(\mathrm{NH}_{4}\right)_{2} \mathrm{SO}_{4}$, calculated for the dry particle radius $0.1 \mu \mathrm{m}$ using the expressions from (Tang 1996). Although the scattering of data in Fig.10 is significant, the value of $f_{\mathrm{r}}(85 \%)$ is estimated to be about 1.3 which is a typical number for the east coast regional haze aerosol (Kotchenruther et al. 1999).

The retrieval of integral particle parameters, such as volume density, is more stable than number density retrievals. Therefore it is interesting to consider the volume growth factor $f_{v}(R H)$ that may be more appropriate for the study of the hygroscopic growth process using multi-wavelength Raman lidar: $f_{v}(R H)=\frac{V(R H)}{V\left(R H_{r e f}\right)}$. Defined this way, $f_{v}(R H)$ represents the amount of water accepted in the process of particle growth. The corresponding results are shown in Fig.11. This factor reveals a smoothly varying dependence on $\mathrm{RH}$, which is due to larger range of volume variation to compare with radius. For comparison, the results from August 27 are also shown. For that day $\mathrm{V}(\mathrm{RH})$ does not follow the model curve which could be another indication of the presence of different aerosol types along the sounding path.

\section{Summary and conclusions}


The main intention of this paper was to demonstrate the ability of the multi-wavelength Raman lidar technique to profile the vertical distribution within the planetary boundary layer of critical aerosol parameters such as mean and effective radius, Ångström exponent, complex refractive index, number and volume densities under varying relative humidity conditions. A newly designed multi-wavelength Raman lidar and upgraded inversion algorithm permits the simultaneous retrieval of microphysical particle parameters at all height in the profile. Regardless of the degree of mixing, the source of aerosols or other considerations, we found a strong positive correlation between RH and aerosol particle extinction, size and volume. To support the results of the lidar measurements, comparisons with column-averaged quantities from a co-located AERONET sun photometer data were performed. The lidar measurements of fine mode parameters agreed well with the sun photometer, but at present, the lidar technique has difficulty in fully representing the coarse mode. A contributing factor could be that the particles exceeding $2 \mu \mathrm{m}$ may have been concentrated at altitudes lower than were retrieved by lidar in this study $(0.5 \mathrm{~km})$, hence our next goal is to decrease the minimum useful altitude of the measurements. These comparisons make particularly clear the need to consider the possibility of hygroscopic growth when interpreting AERONET column-averaged data.

Three datasets were studied in detail. One was characterized by low RH conditions where no evidence of particle growth with increasing $\mathrm{RH}$ was observed and two were acquired under higher RH conditions where a strong correlation was observed between aerosol size and RH. Considering these two latter cases, hygroscopic growth factors were calculated. However the first of the two cases on August 27 was likely characterized by differing aerosol mixtures in the vertical while the second case, that on September 12, 2006, was judged to have both a range of $\mathrm{RH}$ and a fixed aerosol mixture in a portion of the profile making it suitable for calculations of hygroscopic growth parameters. The 
calculated hygroscopic growth curves for these two cases differed considerably with the latter case on September 12 being more consistent with published in literature.

The results presented here demonstrate the potential of the multi-wavelength lidar technique for the study of aerosol hygroscopic growth in the atmosphere. Although the derived hygroscopic growth parameters agree well with modeling, they must be considered preliminary due to the lack of temperature data at the lidar site and the inability of fully resolve the coarse mode of the PSD. For validation of the MW technique, the temporal and spatial separation between lidar and radiosonde measurements should be minimized and cases should be selected where the PSD is dominated by the fine mode. 


\section{REFERENCES}

Ansmann, A., M. Riebesell, U. Wandinger, C. Weitkamp, E. Voss, W. Lahmann, W. Michaelis, "Combined Raman elastic-backscatter lidar for vertical profiling of moisture, aerosols extinction, backscatter, and lidar ratio,” Appl.Phys.B 55, 18 (1992).

Ansmann, A., D. Althausen, U. Wandinger, K. Franke, D. Muller, F. Wagner, and J. Heintzenberg, "Vertical profiling of the Indian aerosol plume with six- wavelength lidar during INDOEX: A first case study,” Geophys. Res. Lett., 27, 963- 966. (2000).

Ansmann, A., F. Wagner, D. Müller, D. Althausen, A. Herber, W. von Hoyningen-Huene, U. Wandinger, "European pollution outbreaks during ACE 2: Optical particle properties inferred from multi-wavelength lidar and star-Sun photometry," J.Geophys. Res., 107, D15, doi:10.1029/2001JD001109 (2002).

Balis, D.S., V. Amiridis, C. Zerefos, E. Gerasopoulos, M. Andreae, P. Zanis, A. Kazantzidis, S. Kazadzis, A. Papayannis, "Raman lidar and sunphotometric measurements of aerosol optical properties over Thessaloniki, Greece during a biomass burning episode”, Atmos. Environ., 37, 4529-4538, (2003).

Carrico, C.M., P.Kus, M.J. Rood, P.K. Quinn and T.S. Bates, "Mixtures of pollution, dust, sea salt, and volcanic aerosol during ACE-Asia: Radiative properties as a function of relative humidity", J. Geophys.Res. 108, 8650, doi:10.1029/2003JD003405 (2003).

Chen, L.-W. A., B.G. Doddridge, R.R. Dickerson, J.C. Chow, and R.C. Henry, "Origins of fine aerosol mass in the Baltimore-Washington corridor: implications from observation, factor analysis and ensemble air parcel back trajectories," Atmos. Environ., 36, 4541-4554 (2002).

D’Almeida, G.A., P. Koepke, E.P. Shettle: in Atmospheric aerosols, edited by: A. Deepak, Global climatology and radiative characteristics, Hampton, VA, USA, 1991.

Dubovik, O., B. Holben, T. Eck, A. Smirnov, Y. Kaufman, M. D. King, D. Tanre, I. Slutsker, "Variability of absorption and optical properties of key aerosol types observed in worldwide locations", J. of Atmos Sci., 59, 590-608 (2002).

Feingold, G. and C.J.Grund, "Feasibility of using multi-wavelength lidar measurements to measure cloud condensation nuclei”, J.Atmos.Ocean. Tech., 11, 1543-1558 (1994).

Feingold, G., B.Morley "Aerosol hygroscopic properties as measured by lidar and comparison with in situ measurements”, J.Geophys.Res., 108, D11, doi:10.1029/2002JD002842 (2003). 
Ferrare, R. A., S. H. Melfi, D. N. Whiteman, K. D. Evans, R. Leifer, and Y. J. Kaufman, “ Raman lidar measurements of aerosol extinction and backscattering: 1. Methods and comparisons”, J. Geophys. Res., 103, 19,663-19,672 (1998a).

Ferrare, R. A., S. H. Melfi, D. N. Whiteman, K. D. Evans, M. Poellot, and Y. J. Kaufman, "Raman lidar measurements of aerosol extinction and backscattering, 2, Derivation of aerosol real refractive index, single-scattering albedo, and humidification factor using Raman lidar and aircraft size distribution measurements”, J. Geophys. Res.,103, 19,673-19,690, (1998b).

Ferrare, R.A., D. Turner, L. Brasseur, W. Feltz, O. Dubovik, T. Tooman, “ Raman lidar measurements of the aerosol extinction-to-backscatter ratio over the Southern Great Plains “, J.Geophys.Res. 106 (D17), 20.333-20.347 (2001).

Fitzgerald, J.W., W.A. Hoppel, and M.A. Vietti, “The size and scattering coefficient of urban aerosol particles at Washington, DC as a function of relative humidity,” J. Atmos. Sci., 39, 1838-1852 (1982).

Fuzzi, S., S.Decesari, M.C. Facchini, E.Matta, M.Mircea, “A simplified model of the water soluble organic component of atmospheric aerosols”, Geophys. Res. Lett. 20, 4079-4082 (2001).

Gasparini, R., R. Li, D. R. Collins, R. A. Ferrare, V. G. Brackett, “Application of aerosol hygroscopicity measured at the Atmospheric Radiation Measurement Program's Southern Great Plains site to examine composition and evolution”, J.Geophys.Res. 111, D05S12, doi:10.1029/2004JD005448 (2006a).

Gasparini, R., D.R.Collins, E.Andrews, P.J.Sheridan, J.A.Ogren, J.G.Hudson, "Coupling aerosol size distribution and size-resolved hygroscopicity to predict humidity-dependent optical properties and cloud condensation nuclei spectra,” J.Geophys.Res. 111, Do5S13, doi:10.1029/2005JD006092 (2006b).

Hanel, G., "The properties of atmospheric aerosol particles as functions of the relative humidity at thermodinamic equilibrium with the surrounding moist air”, Adv. Geophys. 19, 73-188 (1976).

Holben, B.N., T.F.Eck, I.Slutsker, D.Tanre, J.P.Buis, A.Setzer, E.Vermote, J.A.Reagan, Y.Kaufman, T.Nakajima, F.Lavenu, I.Jankowiak, and A.Smirnov, “AERONET - a federated instrument network and data archive for aerosol characterization”, Remote Sens. Environ., 66, 1-16 (1998).

Kolgotin, A., D.Muller, “Theory of inversion with two-dimensional regularization: profiles of microphysical particle properties derived from multiwavelength lidar measurements”, Appl.Opt. 47, $4472-4490$ (2008).

Kotchenruther, R.A. and P.V.Hobbs, "Humidification factors of aerosols from biomass burning in Brazil”, J.Geophys.Res. 103, 32.081-32.089 (1998). 
Kotchenruther, R.A., P.V.Hobbs, D.A.Hegg, "Humidification factors for atmospheric aerosols off the mid-Atlantic coast of the United States”, J.Geophys.Res. 104, D2, 2239-2251 (1999).

Kovalev, V.A., Eichinger W.E., Elastic lidar. Theory, practice and analysis methods. WileyInterscience 2004

Kreidenweis, S.M., M.D.Petters, P.J. DeMott, ”Deliquescence-controlled activation of organic aerosols“, Geophys.Res.Lett. 33, L06801, doi:10.1029/2005GL024863 (2006).

Kumar, P.P., K. Broekhuizen, J.P.D. Abbatt, “Organic acids as cloud condensation nuclei: Laboratory studies of highly soluble and insoluble species”, Atmos.Chem.Phys. 3, 509-520 (2003).

Liu, Z., N.Sugimoto, T.Murayama, "Extinction-to-backscatter ratio of Asian dust observed with highspectral-resolution lidar and Raman lidar”, Appl.Opt. 41, 2760-2767 (2002).

MacKinnon, D.J., "The effect of hygroscopic particles on the backscattered power from a laser beam”, J. Atmos. Sci., 26, 500-510 (1969).

Müller, D., U. Wandinger, and A. Ansmann, "Microphysical particle parameters from extinction and backscatter lidar data by inversion with regularization: theory,” Appl. Opt. 38, 2346-2357 (1999).

Müller, D., U. Wandinger, D. Althausen, and M. Fiebig, "Comprehensive particle characterization from 3-wavelength Raman lidar observations: case study,” Appl. Opt., 40, 4863-4869 (2001).

Müller, D., A.Ansmann, F. Wagner, K. Franke, D. Althausen, "European pollution outbreaks during ACE 2:Microphysical particle properties and single-scattering albedo inferred from multi-wavelength lidar observations,” J. Geophys. Res.107, D15, doi:10.1029/2001JD001110 (2002).

Müller, D., I. Mattis, A. Ansmann, B. Wehner, D. Althausen, U. Wandinger and O. Dubovik, "Closure study on optical and microphysical properties of a mixed urban and Arctic haze air mass observed with Raman lidar and Sun photometer,” J.Geophys. Res. 109, D13206, doi:10.1029/2003JD004200, (2004).

Müller, D., I. Mattis, U. Wandinger, A. Ansmann, D. Althausen, and A. Stohl, "Raman lidar observations of aged Siberian and Canadian forest fire smoke in the free troposphere over Germany in 2003:Microphysical particle characterization,” J.Geophys. Res. 110, D17201, doi:10.1029/2004JD005756, (2005).

Pahlow, M., G.Feingold, A.Jefferson, E.Andrews, J.A.Ogren, J.Wang, Y.-N. Lee. R.A.Ferrare, D.D.Turner, "Comparison between lidar and nephelometer measurements of aerosol hygroscopicity at the Southern Great Plains Atmospheric Radiation Measurement site”, J.Geophys.Res., 111, D05S15, doi:10.1029/2004JD005646 (2006). 
Park, S.S., J.Kliessl, D.Harrison, V.Kumar, N.P.Nair, M.Adam, J.Ondov, and M.Parlange, "Characteristics of PM2.5 episodes revealed by semi-continuous measurements at the Baltimore supersite at Ponca St.,” Aerosol Sci. Technol., 40, 845-860 (2006).

Pilinis, C., S.N. Pandis, and J.H. Seinfeld, "Sensitivity of a direct climate forcing by atmospheric aerosols to aerosol size and composition”, J.Geophys.Res. 100 (D9), 18,739-18,754 (1995).

Randriamiarisoa, H., P. Chazette, P. Couvert, J. Sanak, G. Megie, "Relative humidity impact on aerosol parameters in a Paris suburban area”, Atmos. Chem. Phys., 6, 1389-1407, (2006).

Raut, J.-C., and P.Chazette, "Retrieval of aerosol complex refractive index from a synergy between lidar, sun photometer and in situ measurements during LISAIR experiment”, Atmos. Chem. Phys., 7, 2797-2815 (2007).

Shipley, S. A., D. H. Tracy, E. W. Eloranta, J. T. Trauger, J. T. Sroga, F. L. Roesler, and J. A. Weinman, "High spectral resolution lidar to measure optical scattering properties of atmospheric aerosol, 1, Theory and instrumentation”, Appl. Opt., 23, 3716-3724, (1983).

Svenningsson, B., J. Rissler, E. Swietlicki, M. Mircea, M. Bilde, M.C. Facchini, S. Decesari, S. Fuzzi, J. Zhou, J. Monster, T. Rosenorn, "Hygroscopic growth and critical supersaturations for mixed aerosol particles of inorganic and organic compounds of atmospheric relevance”, Atmos.Chem.Phys. 6, 19371952 (2006).

Tang, I., and H. Munkelwitz, "Composition and temperature dependence of the deliquescence properties of hygroscopic aerosols”, Atmospheric Environment 27A, 467-473 (1993).

Tang, I., "Chemical and size effects of hygroscopic aerosol on light scattering coefficients," $J$. Geophys. Res., 101, D14, 19245-19250 (1996).

Tikhonov, A.N., and V.Y.Arsenin, eds., Solution of Ill-Posed Problems (Wiley, New York, 1977).

Turner, D.D., R. A. Ferrare, L. A. Heilman-Brasseur, W. F. Feltz, and T. P. Tooman, “Automated retrievals of water vapor and aerosol profiles from an operational Raman lidar," J. Atmos. Oceanic Technol., 19, 37- 50 (2002).

Twomey. S., ed., Introduction to the Mathematics of Inversion in Remote Sensing and Direct Measurements (Elsevier, New York, 1977).

Veselovskii, I., A. Kolgotin, V. Griaznov, D. Müller, U. Wandinger, D. Whiteman. "Inversion with regularization for the retrieval of tropospheric aerosol parameters from multi-wavelength lidar sounding”, Appl.Opt. 41, 3685-3699 (2002). 
Veselovskii, I., A. Kolgotin, V. Griaznov, D. Müller, K. Franke, D.N. Whiteman. "Inversion of multiwavelength Raman lidar data for retrieval of bimodal aerosol size distribution”, Appl.Opt. 43, 11801195 (2004).

Veselovskii, I., A. Kolgotin, D. Müller, D. N. Whiteman. "Information content of multi-wavelength lidar data with respect to microphysical particle properties derived from eigenvalue analysis”, Appl. Opt. 44, 5292-5303 (2005).

Wexler, A.,: Vapor pressure formulation for water in range 0 to $100^{\circ} \mathrm{C}$ : A revision. J. Res. Nat. Bur. Stand., 80A, 775-785 (1976).

Whiteman, D. N., S.H. Melfi, R.A. Ferrare, "Raman Lidar System for Measurement of Water Vapor and Aerosols in the Earth's Atmosphere", Appl. Opt. 31 No. 163068 - 3082 (1992).

Whiteman, D. N., S. H. Melfi, Cloud liquid water, mean droplet radius and number density measurements using a Raman lidar, J. Geophys. Res., Vol 104 No. D24, 31411-31419 (1999)

Whiteman, D. N., "Examination of the traditional Raman lidar technique. I. Evaluating the temperature-dependent lidar equations”, Applied Optics, 42, No. 15, 2571-2592 (2003a).

Whiteman, D. N., "Examination of the traditional Raman lidar technique. II. Evaluating the ratios for water vapor and aerosols”, Applied Optics, 42, No. 15, 2593-2608 (2003b).

Whiteman, D.N., I. Veselovskii, M.Cadirola, K. Rush, J.Comer, J.R.Potter, R. Tola, "Demonstrations measurements of water vapor, cirrus clouds, and carbon dioxide using a high-performance Raman lidar”, J. Atmos. Oceanic Technol. 24, 1377-1388 (2007).

Wulfmeyer, V., G.Feingold, “On the relationship between relative humidity and particle backscattering coefficient in the marine boundary layer determined with differential absorption lidar", J.Geophys.Res., 105, 4729-4741 (2000). 


\section{Tables}

Table 1. Column integrated aerosol parameters derived from lidar and AERONET on 16 August 2006.

\begin{tabular}{|l|l|l|l|}
\hline \multicolumn{2}{|l|}{ Parameter } & AERONET & Lidar \\
\hline AOT & $355 \mathrm{~nm}$ & $0.32 \pm 0.015$ & $0.3 \pm 0.03$ \\
\cline { 2 - 4 } & $532 \mathrm{~nm}$ & $0.18 \pm 0.009$ & $0.18 \pm 0.018$ \\
\hline $\mathrm{V}^{\text {tot }}\left(\mu \mathrm{m}^{3} / \mu \mathrm{m}^{2}\right)$ & $0.056 \pm 0.005$ & $0.035 \pm 0.007$ \\
\hline $\mathrm{V}^{\text {fine }}\left(\mu \mathrm{m}^{3} / \mu \mathrm{m}^{2}\right)$ & $0.029 \pm 0.004$ & $0.025 \pm 0.005$ \\
\hline$r_{\text {eff }}^{\text {tot }}(\mu \mathrm{m})$ & $0.22 \pm 0.06$ & $0.21 \pm 0.04$ \\
\hline$r_{\text {eff }}^{\text {fine }}(\mu \mathrm{m})$ & & $0.15 \pm 0.03$ \\
\hline $\mathrm{m}_{\mathrm{R}}$ & $0.123 \pm 0.035$ & $1.45 \pm 0.05$ \\
\hline $\mathrm{m}_{\mathrm{I}}$ & & $0.01 \pm 0.005$ \\
\hline
\end{tabular}


Table 2. Column integrated aerosol parameters derived from lidar and AERONET on 12 September 2006.

\begin{tabular}{|l|l|l|l|}
\hline \multicolumn{2}{|l|}{ Parameter } & AERONET & Lidar \\
\hline \multirow{2}{*}{ AOT } & $355 \mathrm{~nm}$ & $0.38 \pm 0.019$ & $0.41 \pm 0.08$ \\
\cline { 2 - 4 } & $532 \mathrm{~nm}$ & $0.27 \pm 0.013$ & $0.31 \pm 0.06$ \\
\hline $\mathrm{V}^{\text {tot }}\left(\mu \mathrm{m}^{3} / \mu \mathrm{m}^{2}\right)$ & & $0.076 \pm 0.015$ \\
\hline $\mathrm{V}^{\text {fine }}\left(\mu \mathrm{m}^{3} / \mu \mathrm{m}^{2}\right)$ & $0.073 \pm 0.007$ & $0.057 \pm 0.012$ \\
\hline$r_{\text {eff }}^{\text {tot }}(\mu \mathrm{m})$ & $0.05 \pm 0.0075$ & $0.33 \pm 0.07$ \\
\hline$r_{\text {eff }}^{\text {fine }}(\mu \mathrm{m})$ & $0.301 \pm 0.09$ & $0.25 \pm 0.05$ \\
\hline $\mathrm{m}_{\mathrm{R}}$ & $0.21 \pm 0.06$ & $1.34 \pm 0.05$ \\
\hline $\mathrm{m}_{\mathrm{I}}$ & & $0.009 \pm 0.0045$ \\
\hline
\end{tabular}




\section{Captures to the figures}

Fig.1. Lidar signal at $1064 \mathrm{~nm}$ measured on 2 September, 2006 together with simulated Raleigh signal (dash-dot).

Fig.2. Vertical profiles of aerosol backscattering (solid) and extinction (dash-dot) coefficients at 355, 532 and $1064 \mathrm{~nm}$ measured on 22 August 2006.

Fig 3. Vertical profiles of aerosol parameters measured on 16 August: (a) water vapor mixing ratio $\mathrm{w}_{\mathrm{M}}$ and relative humidity $\mathrm{RH}$ derived from the lidar data (solid lines) and from the sonde measurements (line+symbol); (b) aerosol extinction coefficients at $355 \mathrm{~nm}$ together with Ångström exponent $k$; (c) mean $\mathrm{r}_{\text {mean }}$ and effective $\mathrm{r}_{\text {eff }}$ radius, dashed line shows the effective radius for the fine mode $\left(\mathrm{r}_{\text {eff }}^{\text {fine }}\right)$ and for the total size distribution ( $\left.\mathrm{r}_{\text {eff }}^{\text {tot }}\right)$ obtained by AERONET; (d) number $\mathrm{N}$ and volume $V$ density; (e) real $m_{R}$ and imaginary $m_{I}$ part of refractive index, dotted lines show the results from AERONET.

Fig.4. Particle size distribution derived from lidar measurements at altitudes 1.1 and 1.7.km on 16 August. Open symbols show the columnar PSD from AERONET.

Fig.5. Vertical profiles of aerosol parameters measured on 27 August: (a) water vapor mixing ratio $\mathrm{w}_{\mathrm{M}}$ and relative humidity $\mathrm{RH}$ derived from the lidar data (solid lines) and from the sonde measurements (line+symbol); (b) aerosol extinction coefficients at $355 \mathrm{~nm}$ together with Ångström exponent $k$; (c) mean $\mathrm{r}_{\text {mean }}$ and effective $\mathrm{r}_{\text {eff }}$ radius, dashed line shows the effective radius for the fine mode $\left(\mathrm{r}_{\text {eff }}^{\text {fine }}\right)$ and for the total size distribution ( $\left.\mathrm{r}_{\text {eff }}^{\text {tot }}\right)$ obtained by AERONET; (d) number $\mathrm{N}$ and volume $\mathrm{V}$ density; (e) real $\mathrm{m}_{\mathrm{R}}$ and imaginary $\mathrm{m}_{\mathrm{I}}$ part of refractive index, dotted lines show the results from AERONET.

Fig.6. Vertical profiles of aerosol parameters measured on 12 September : (a) water vapor mixing ratio $\mathrm{w}_{\mathrm{M}}$ and relative humidity $\mathrm{RH}$ derived from the lidar data; (b) aerosol extinction coefficients at $355 \mathrm{~nm}$ together with Ångström exponent $k$; (c) mean $r_{\text {mean }}$ and effective $r_{\text {eff }}$ radius, dashed line 
shows the effective radius for the fine mode $\left(\mathrm{r}_{\text {eff }}^{\text {fine }}\right)$ and for the total size distribution $\left(\mathrm{r}_{\text {eff }}^{\mathrm{tot}}\right)$ obtained by AERONET; (d) number $\mathrm{N}$ and volume $\mathrm{V}$ density; (e) real $\mathrm{m}_{\mathrm{R}}$ and imaginary $\mathrm{m}_{\mathrm{I}}$ part of refractive index, dotted lines show the results from AERONET.

Fig.7 Correlation between lidar derived Ångström exponent and effective radius. Solid stars represent the results for AERONET on 16 August and 12 September.

Fig.8. $f(\mathrm{RH})$ from the dataset of August 27, 2006 for the ranges $800-2000 \mathrm{~m}$ (stars) and $2000-$ $2600 \mathrm{~m}$ (squares). For these ranges two distinct source regions for aerosols were identified by back trajectory analysis. Solid line represents the parameterization fit of $f(\mathrm{RH})$ for $\mathrm{g}=0.9$.

Fig.9. Dependence of extinction coefficient at $532 \mathrm{~nm}$ on $\mathrm{RH}$ and humidification factor $f(\mathrm{RH})$ derived from 12 September data. Results are shown for altitude ranges: 1.0-1.3 km (solid squares), $1.3-1.8 \mathrm{~km}$ (open stars) and 1.8-2.5 km (open circles). Solid line represents the parameterization fit of $f(\mathrm{RH})$ for $\mathrm{g}=0.9$.

Fig.10. Dependence of aerosol mean radius on RH derived from 12 September 2006 data together with size growth factor $f_{\mathrm{r}}(\mathrm{RH})$. Solid line shows the hygroscopic growth of $\left(\mathrm{NH}_{4}\right)_{2} \mathrm{SO}_{4}$ particle with $\mathrm{r}_{0}=0.1 \mu \mathrm{m}$.

Fig. 11. Dependence of aerosol volume concentration on RH derived from 12 September 2006 data together with volume growth factor. For comparison the results from 27 August, when the condition of well mixing are not fulfilled are also shown. 


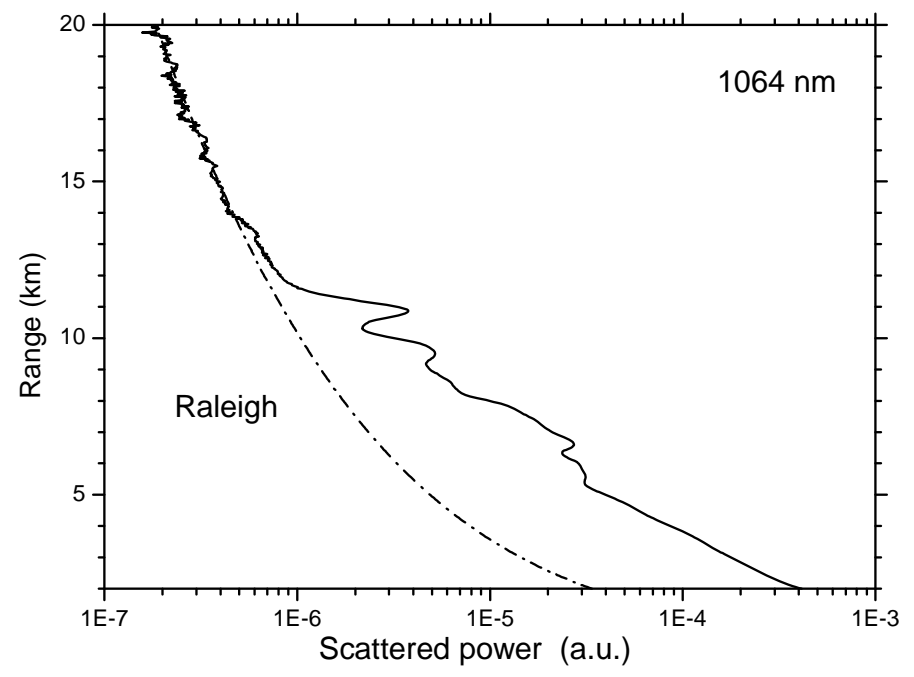

Fig.1. Lidar signal at $1064 \mathrm{~nm}$ measured on 2 September, 2006 together with simulated Raleigh signal (dash-dot). 


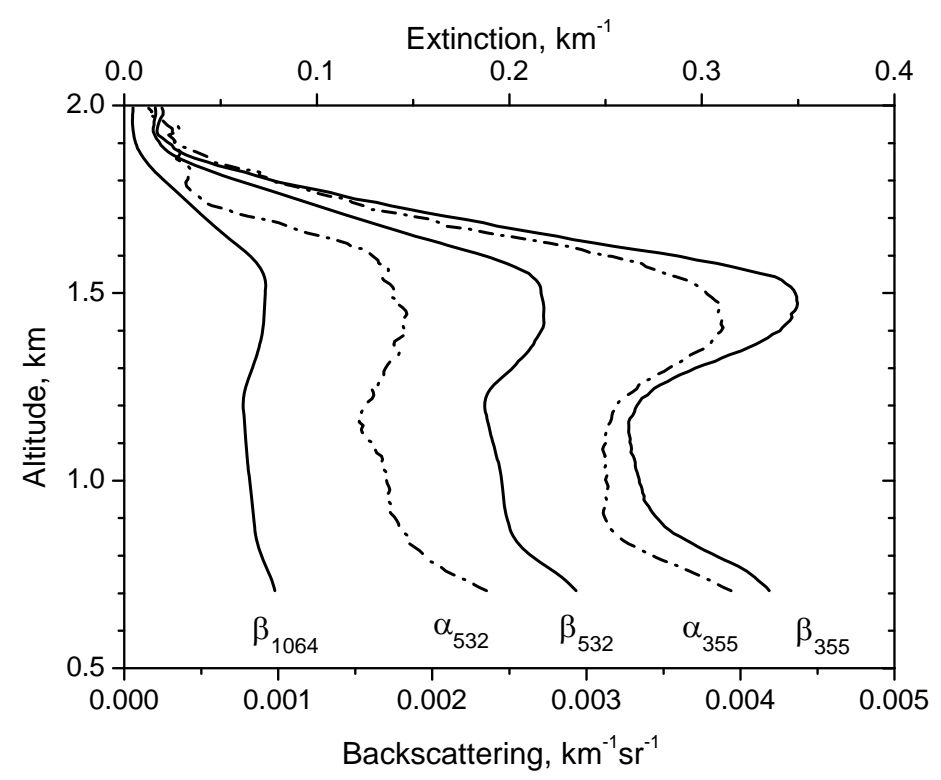

Fig.2. Vertical profiles of aerosol backscattering (solid) and extinction (dash-dot) coefficients at 355, 532 and $1064 \mathrm{~nm}$ measured on 22 August 2006. 

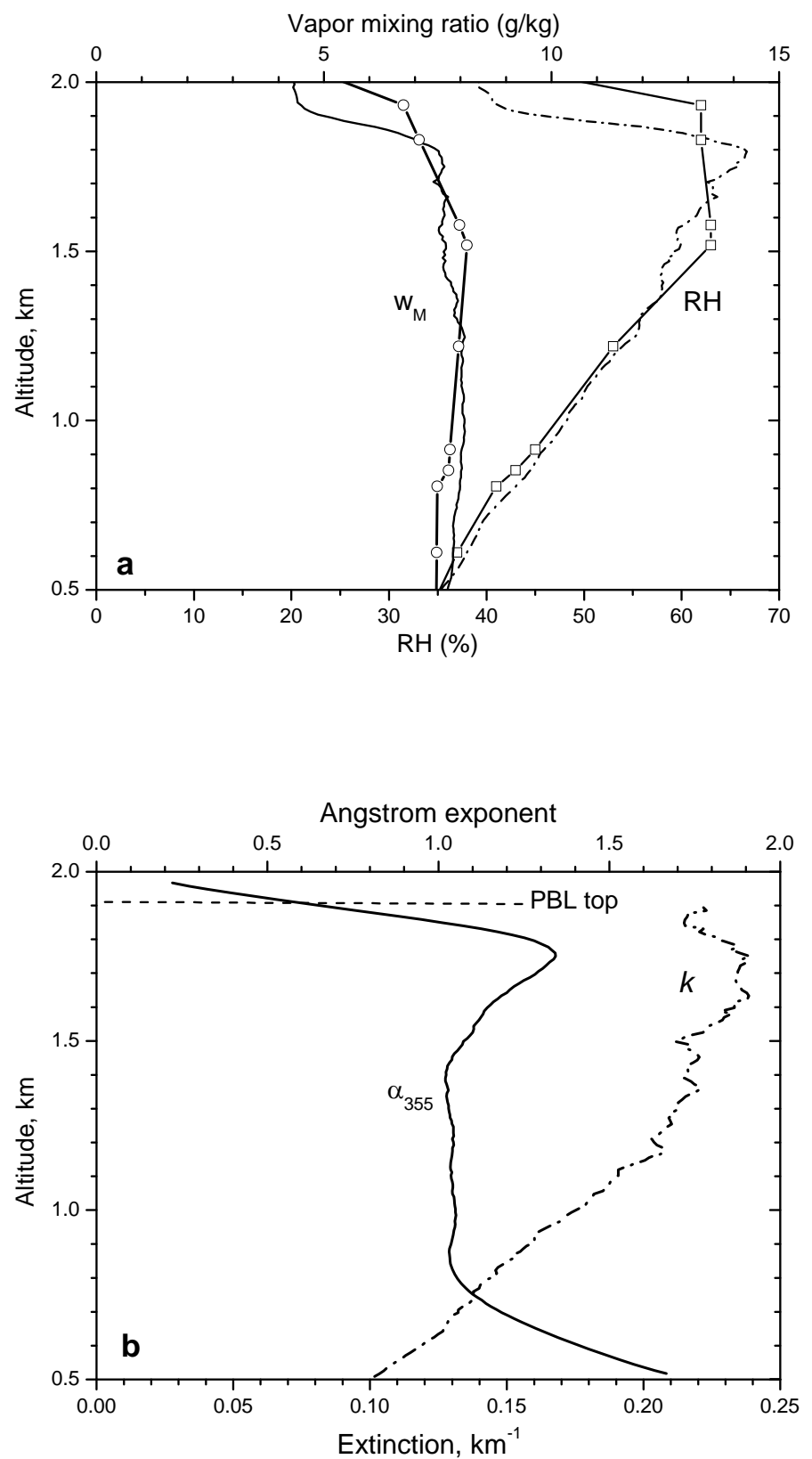

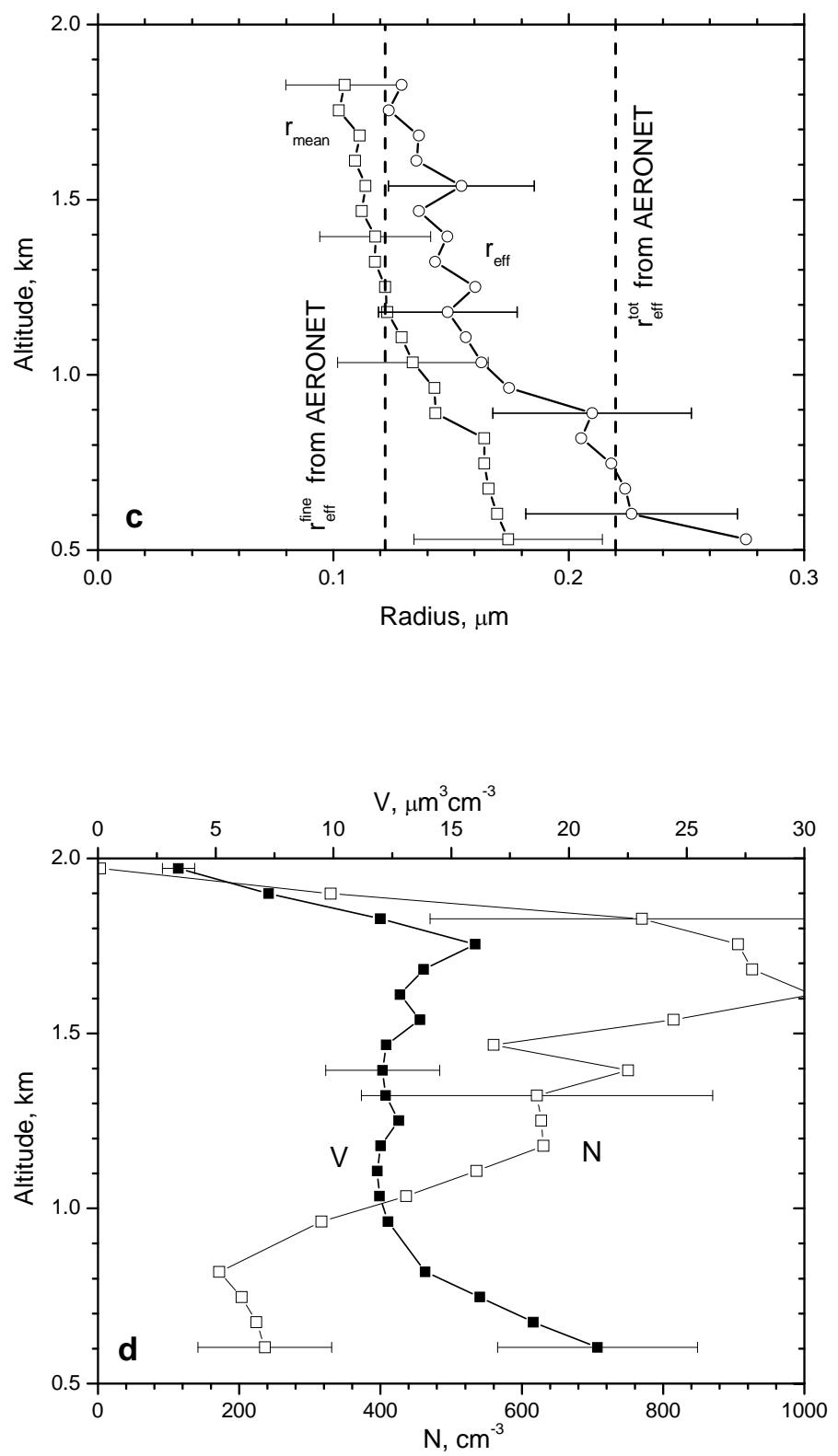




Fig.3. Vertical profiles of aerosol parameters measured on 16 August: (a) water vapor mixing ratio $\mathrm{w}_{\mathrm{M}}$ and relative humidity $\mathrm{RH}$ derived from the lidar data (solid lines) and from the sonde measurements (line+symbol); (b) aerosol extinction coefficients at $355 \mathrm{~nm}$ together with Ångström exponent $k$; (c) mean $\mathrm{r}_{\text {mean }}$ and effective $\mathrm{r}_{\text {eff }}$ radius, dashed line shows the effective radius for the fine mode ( $\mathrm{r}_{\text {eff }}^{\text {fine }}$ ) and for the total size distribution ( $\mathrm{r}_{\text {eff }}^{\text {tot }}$ ) obtained by AERONET; (d) number $\mathrm{N}$ and volume V density; (e) real $m_{R}$ and imaginary $m_{I}$ part of refractive index, dotted lines show the results from AERONET. 




Fig.4. Particle size distribution derived from lidar measurements at altitudes 1.1 and 1.7.km on 16 August. Open symbols show the columnar PSD from AERONET. 

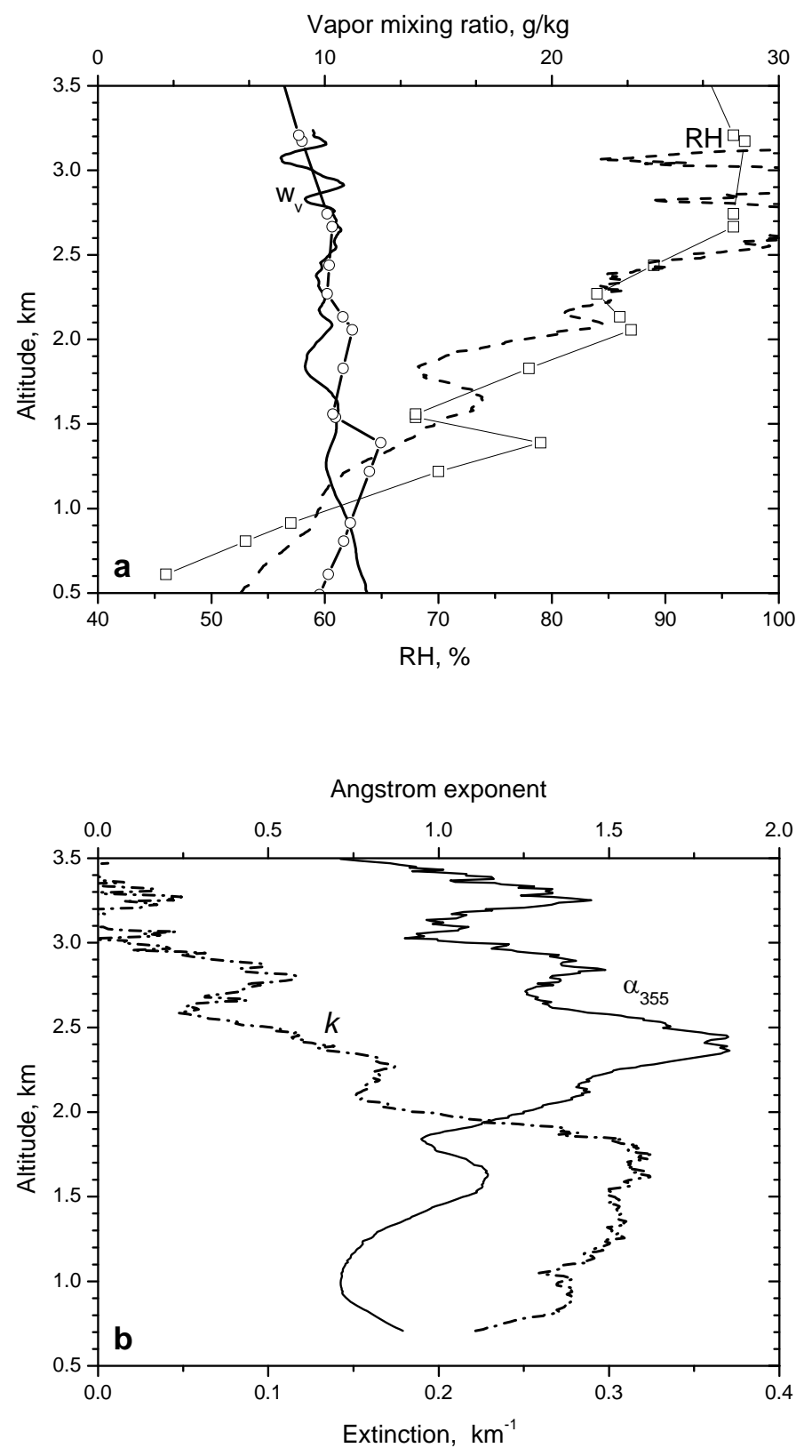

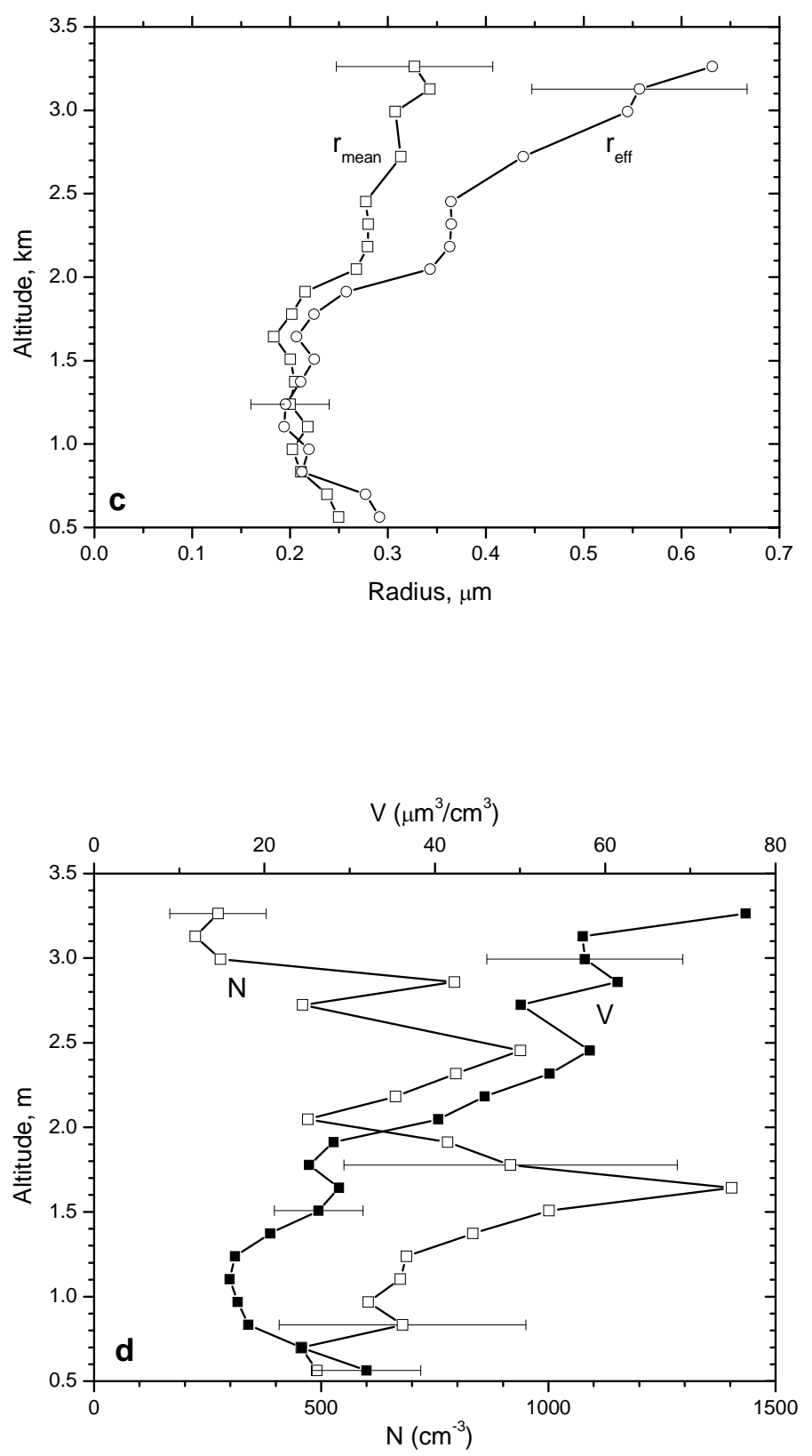


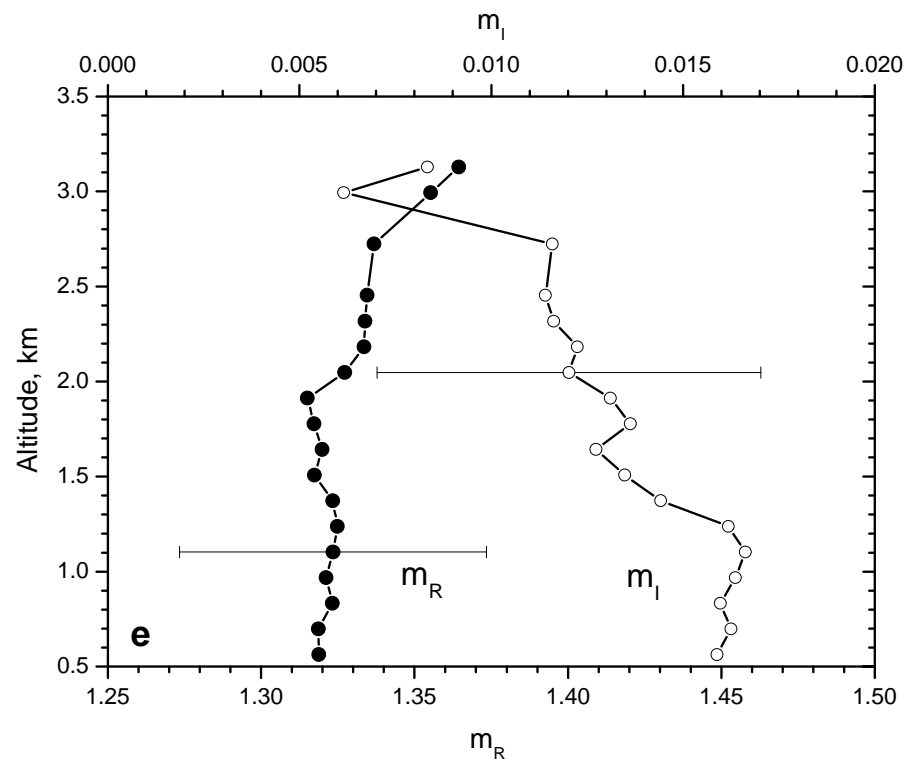

Fig.5. Vertical profiles of aerosol parameters measured on 27 August: (a) water vapor mixing ratio $\mathrm{w}_{\mathrm{M}}$ and relative humidity $\mathrm{RH}$ derived from the lidar data (solid lines) and from the sonde measurements (line+symbol); (b) aerosol extinction coefficients at 355 nm together with Ångström exponent $k$; (c) mean $r_{\text {mean }}$ and effective $r_{\text {eff }}$ radius, dashed line shows the effective radius for the fine mode $\left(\mathrm{r}_{\text {eff }}^{\text {fine }}\right)$ and for the total size distribution $\left(\mathrm{r}_{\text {eff }}^{\text {tot }}\right.$ ) obtained by AERONET; (d) number $\mathrm{N}$ and volume $\mathrm{V}$ density; (e) real $\mathrm{m}_{\mathrm{R}}$ and imaginary $\mathrm{m}_{\mathrm{I}}$ part of refractive index, dotted lines show the results from AERONET. 



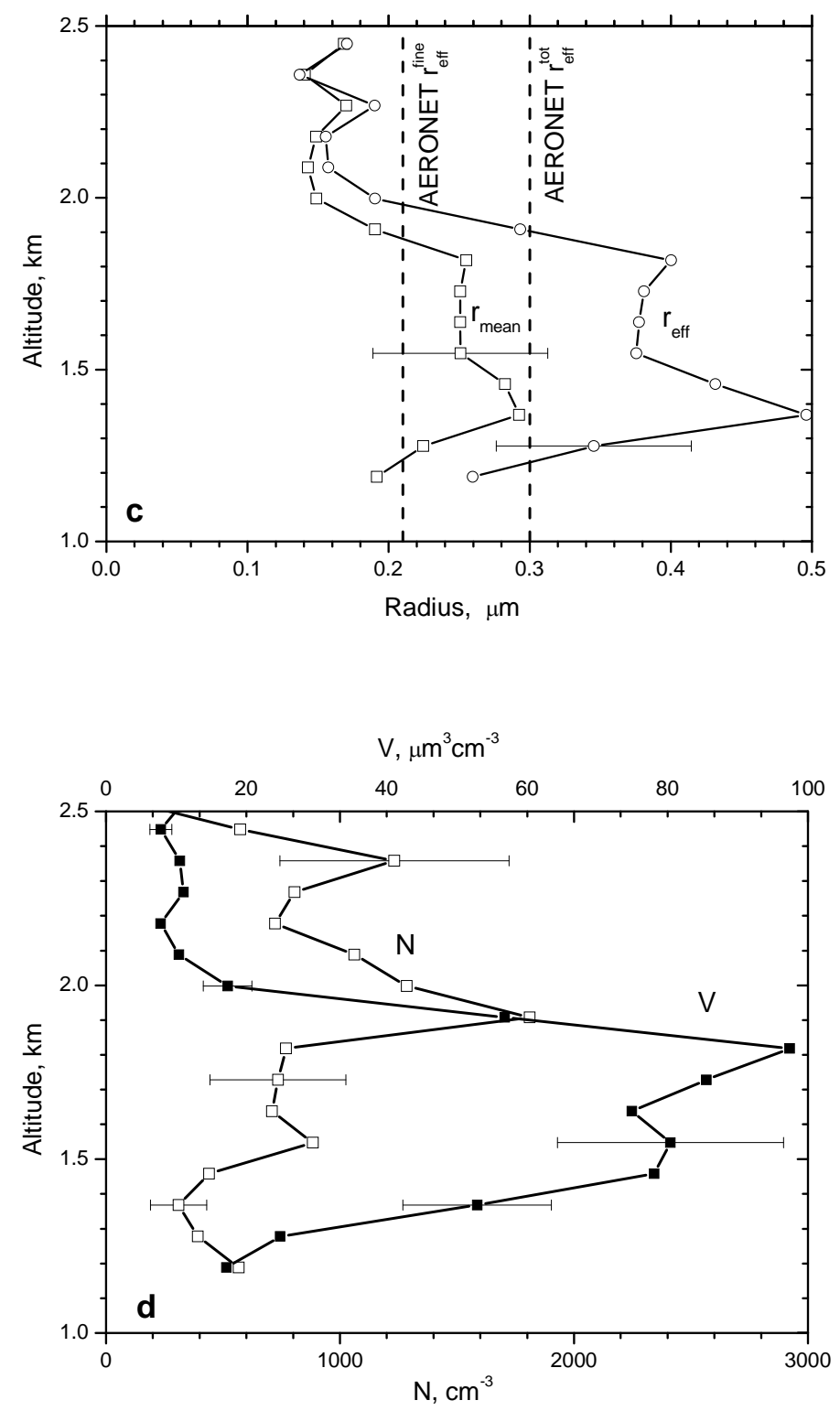


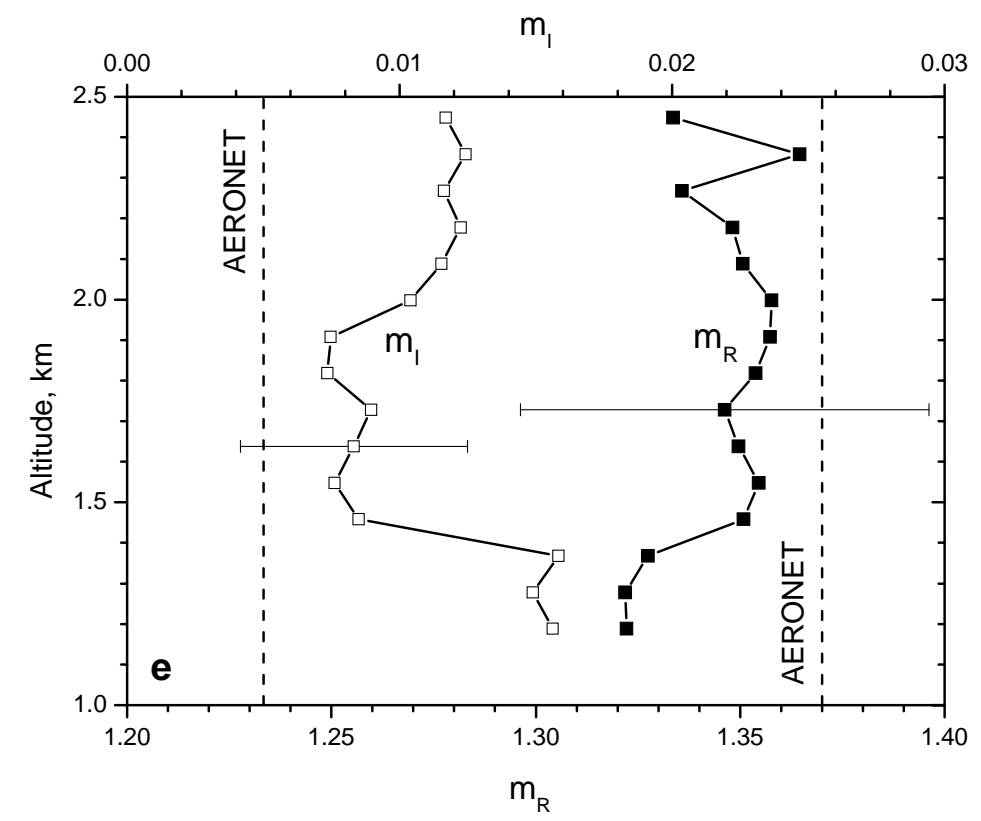

Fig.6. Vertical profiles of aerosol parameters measured on 12 September : (a) water vapor mixing ratio $\mathrm{w}_{\mathrm{M}}$ and relative humidity RH derived from the lidar data; (b) aerosol extinction coefficients at $355 \mathrm{~nm}$ together with Ångström exponent $k$; (c) mean $\mathrm{r}_{\text {mean }}$ and effective $\mathrm{r}_{\text {eff }}$ radius, dashed line shows the effective radius for the fine mode $\left(\mathrm{r}_{\text {eff }}^{\text {fin }}\right)$ and for the total size distribution $\left(\mathrm{r}_{\text {eff }}^{\mathrm{tot}}\right)$ obtained by AERONET; (d) number $\mathrm{N}$ and volume $\mathrm{V}$ density; (e) real $\mathrm{m}_{\mathrm{R}}$ and imaginary $\mathrm{m}_{\mathrm{I}}$ part of refractive index, dotted lines show the results from AERONET. 


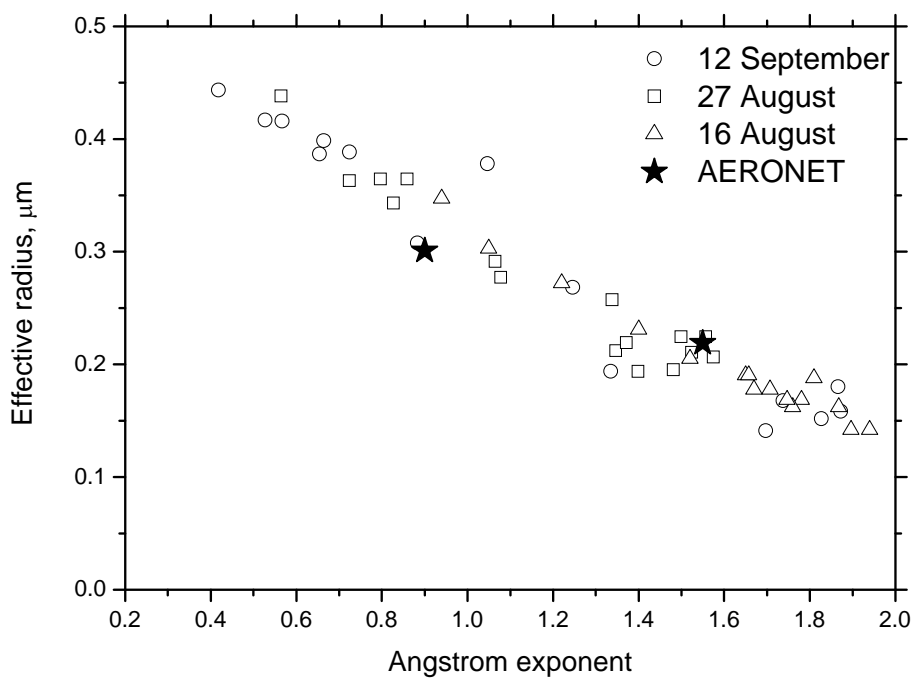

Fig.7. Correlation between lidar derived Ångström exponent and effective radius. Solid stars represent the results for AERONET on 16 August and 12 September. 




Fig. 8. $f(\mathrm{RH})$ from the dataset of August 27, 2006 for the ranges $800-2000 \mathrm{~m}$ (stars) and $2000-2600$ $\mathrm{m}$ (squares). For these ranges two distinct source regions for aerosols were identified by back trajectory analysis. Solid line represents the parameterization fit of $f(\mathrm{RH})$ for $\mathrm{g}=0.9$. 




Fig 9. Dependence of extinction coefficient at $532 \mathrm{~nm}$ on $\mathrm{RH}$ and humidification factor $f(\mathrm{RH})$ derived from 12 September data. Results are shown for altitude ranges: 1.0-1.3 km (solid squares), $1.3-1.8 \mathrm{~km}$ (open stars) and 1.8-2.5 km (open circles). Solid line represents the parameterization fit of $f(\mathrm{RH})$ for $g=0.9$. 


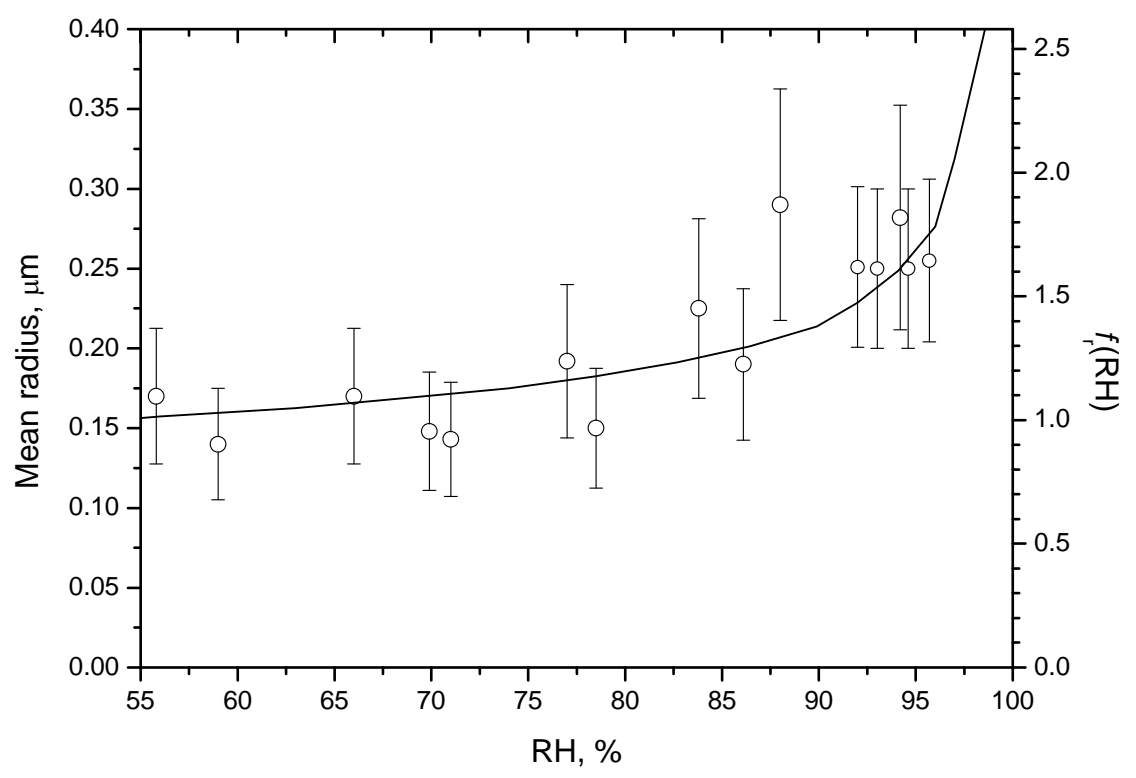

Fig.10. Dependence of aerosol mean radius on RH derived from 12 September 2006 data together with size growth factor $f_{\mathrm{r}}(\mathrm{RH})$. Solid line shows the hygroscopic growth of $\left(\mathrm{NH}_{4}\right)_{2} \mathrm{SO}_{4}$ particle with $\mathrm{r}_{0}=0.1$ $\mu \mathrm{m}$. 




Fig.11. Dependence of aerosol volume concentration on RH derived from 12 September 2006 data together with volume growth factor. For comparison the results from 27 August, when the condition of well mixing are not fulfilled are also shown. 